\title{
Poverty and inequality in the UK: 2007
}

Mike Brewer

Alissa Goodman

Alistair Muriel

Luke Sibieta

The Institute for Fiscal Studies 


\section{Poverty and Inequality in the UK: 2007}

\section{Mike Brewer, Alissa Goodman, Alastair Muriel and Luke Sibieta}

\section{Summary}

This Briefing Note provides an update on trends in living standards, income inequality and poverty. It uses the same approach to measuring income and poverty as the government employs in its Households Below Average Income (HBAI) publication.

The analysis is based on the latest HBAl figures (published on 27 March 2007), providing information about incomes up to the year 2005-06.

The measure of income used is net household weekly income, which has been adjusted to take account of family size ('equivalised'). The income amounts provided below are expressed as the equivalent for a couple with no children, and all changes given are in real terms (i.e. after adjusting for inflation).

For the first time in recent years, data are available for the whole of the United Kingdom, not just Great Britain, but data for Northern Ireland are only available from 2002-03. Some comparisons over time are provided for Great Britain only, but others will compare statistics for GB before 2002-03 with those for the UK afterwards.

\section{Living standards and inequality}

Median equivalised disposable income in Great Britain in 2005-06 was £363 per week: half the population have higher incomes than this and half lower. This amount is considerably lower than the average (mean) income of $£ 445$ per week.

For the fourth year in a row, both mean and median income grew modestly compared with the growth during Labour's first term: median income was 1.0\% higher in 200506 than in 2004-05, and mean income 1.3\% higher. These represent much smaller rises than the average annual rises since 1996-97, which have been $2.0 \%$ for median income and $2.3 \%$ for the mean. There is now clear evidence that the rapid growth in household disposable income experienced in the government's first term came to a halt after 2001-02.

Income growth since 2004-05 has tended to be faster the higher are incomes: while median income grew by $1.0 \%$, incomes amongst the poorest fifth of the UK fell by $0.4 \%$, and incomes of the richest fifth rose by $1.5 \%$, though it should be noted that none of these changes is significantly different from the others or from zero.

Many measures of income inequality rose slightly between 2004-05 and 2005-06. According to the most common measure, the Gini coefficient, income inequality in 2005-06 has reached its highest level since 2001-02, and is once again statistically significantly higher than that which the Labour government inherited. On the other hand, other measures of inequality that do not take into account incomes at the very top and very bottom of the income distribution, such as the 90:10 ratio, have fallen since 1996-97. 
Without tax and benefit reforms, which have favoured low-income households, the rise in inequality since 1996-97 would have been much greater, however.

\section{Relative poverty}

The number of people in relative poverty (living in households with less than $60 \%$ of the median income) rose between 2004-05 and 2005-06 from 12.1 million to 12.7 million measuring incomes after housing costs (AHC), and from 10.0 million to 10.4 million measuring incomes before housing costs $(\mathrm{BHC})$. This is the first rise in the rate of relative poverty since 1996-97 (AHC) or 1997-98 (BHC), and it occurred for a range of relative poverty lines and is very unlikely to be due solely to sampling error. The rise is a direct consequence of the weak growth in incomes at the bottom of the income distribution compared with that of the median (the middle).

However, the small rise since 2004-05 in no way offsets the considerable fall in relative poverty since 1996-97: since that time, the risk of relative poverty has fallen from $25.3 \%$ to $21.6 \%(\mathrm{AHC})$ and from $19.4 \%$ to $17.6 \%(\mathrm{BHC})$.

Not all groups have seen a rise in relative poverty since 2004-05: child poverty rose, and the number of working-age adults in poverty also rose. Amongst the latter group, poverty rates for working-age adults without dependent children rose to their highest levels since 1961 (the first year consistent estimates are available). But the number of pensioners in relative poverty continued to fall.

Last year, the government narrowly missed its target for child poverty to fall by a quarter from its level in 1998-99. Although the target does not apply to 2005-06, the government is now further adrift, with child poverty in 2005-06 being only 14\% (AHC) or $18 \%$ (BHC) lower than it was in 1998-99.

The government's next target is for child poverty in 2010-11 to be half its 1998-99 level. Achieving this requires child poverty to fall by an average of over 200,000 in each of the next five years, after average annual falls of less than 100,000 over the past seven years.

A year ago, researchers predicted that an increase in spending of $£ 4.5$ billion a year by 2010-11 would give the government a 50:50 chance of meeting its target. Measures announced in Budget 2007 should have the effect of reducing the child poverty rate. Our revised estimate taking these measures into account is that additional new spending of around $£ 4$ billion a year (on the per-child element of the child tax credit) by 2010-11 is still needed for the government to have a 50:50 chance of meeting its target. The state of the public finances suggests that finding a sum of this magnitude will require a very tight settlement on areas of public services such as the NHS, defence, transport and environmental protection in the forthcoming Comprehensive Spending Review, or substantial savings in existing social security programmes, or new tax-raising measures. If the Labour government is committed to achieving the halving of child poverty, it will have until Autumn 2009, when the tax credits and benefit rates for April 2010 need to be announced, to find the necessary funds. 


\section{Introduction}

In this Briefing Note, we assess the changes to living standards that have occurred under the first nine years of the Labour government, setting out how average incomes, income inequality and poverty have changed between 199697 and 2005-06. We compare these changes with what happened under previous governments, and highlight particularly what changes have occurred in the latest year of the data.

The analysis is based on the latest figures from the Department for Work and Pensions's Households Below Average Income (HBAI) series, published on 27 March 2007. ${ }^{1}$ The HBAI series takes household income as its measure of living standards. The income measure is derived from the Family Resources Survey, a survey of around 28,000 households in the United Kingdom (of which around 26,000 are in Great Britain and 1,900 in Northern Ireland) that asks detailed questions about income from a wide range of sources. Income in HBAI is:

- a snapshot measure, meaning that it will reflect 'actual' or, in some cases, 'usual' income around the time of interview;

- a measure of household income, summed across all members of a household;

- rescaled ('equivalised') to take into account the fact that households of different size and composition have different needs. This year, the HBAI statistics for the first time use the 'modified OECD equivalence scale', rather than the McClements scale. ${ }^{2}$ Note that all income amounts in this Briefing Note are expressed as the equivalent income for a couple with no children;

- a measure of disposable income, which is measured after income tax, employee and self-employed National Insurance contributions, and council $\operatorname{tax}$

- measured both before housing costs have been deducted (BHC) and after they have been deducted (AHC).

\footnotetext{
${ }^{1}$ Department for Work and Pensions, Households Below Average Income 1994/95-2005/06, Corporate Document Services, Leeds, 2007.

${ }^{2}$ For more information on how this affects the HBAI statistics, and, in particular, estimated poverty rates, see the appendix to this year's HBAI report (DWP, 2007, op. cit.).
} 


\section{Box 1. United Kingdom or Great Britain?}

This year's Households Below Average Income publication is the first in recent years to produce its statistics for the whole of the United Kingdom, rather than for Great Britain only. This has been enabled by the relatively recent inclusion of Northern Ireland households in the Family Resources Survey, making it possible to present HBAI statistics on a UK basis back to 2002-03.

In this Briefing Note, we present some analysis at the UK level and some at the GB level. The convention we apply is different in different parts of our analysis. Boxes 2 and 4 provide further details.

The latest available HBAI figures are up to the financial year 2005-06. Because HBAI figures are calculated from a sample of households, rather than from the full population, there is necessarily a degree of uncertainty surrounding the results derived from them. We discuss the degree of uncertainty in the statistics we present throughout our analysis. A more detailed discussion of the HBAI income measure and its advantages and limitations can be found in Brewer et al. (2005). ${ }^{3}$

HBAI is the most reliable source of information when looking at the entire distribution of income or the incomes of subgroups (e.g. 'the poor', 'families with children'). If we are interested in what has happened just to the average income (captured by the mean), then there are a number of other useful sources for analysing this, based on the National Accounts. Appendix 1 compares HBAI information on average incomes with information contained in the National Accounts. Comparisons of this sort are only possible for changes in mean income, because the National Accounts do not tell us anything about individual households.

\section{Living standards}

In this section, we discuss how average incomes have changed in the most recent year of the HBAI data, 2005-06, and since 1996-97. All monetary values in this section are expressed in average 2005-06 prices, and so all the differences we refer to are unaffected by inflation. Since all incomes have been 'equivalised' (see Section 1), all income amounts are expressed as the equivalent income for a couple with no children. We show that average incomes (measured both by the mean and by the median) have continued to

\footnotetext{
${ }^{3}$ M. Brewer, A. Goodman, J. Shaw and L. Sibieta, Poverty and Inequality in Britain: 2006, Commentary no. 101, IFS, London, 2006 (http://www.ifs.org.uk/comms/comm101.pdf).
} 
grow relatively slowly in the last year, but taking the period from 1996-97 to 2005-06, living standards in Great Britain have risen on average by the equivalent of $2.3 \%$ per year at the mean and $2.0 \%$ at the median. ${ }^{4}$ (See Box 2 for our conventions about using UK or GB statistics in this section and in Section 3.)

\section{Box 2. UK or GB when measuring living standards and inequality?}

In Sections 2 and 3, where we set out changes to average living standards and inequality, most of the analysis is presented on a GB basis, to allow consistent comparisons over long periods of time. The only figures presented on a UK basis in Sections 2 and 3 are those surrounding Figure 1, which presents some facts about the UK income distribution in 2005-06.

First, we set out a picture of the UK income distribution in 2005-06.

\subsection{A picture of the income distribution in 1996-97 and 2005-06}

Figure 1 shows the UK income distribution in 2005-06. ${ }^{5}$ The graph shows the number of people living in households with different income levels, grouped into $£ 10$ income bands. The height of the bars represents the number of people in each income band. As can be seen, the current distribution is highly skewed, with $64 \%$ of individuals having household incomes below the national average. Furthermore, the final bar of the graph shows that 1.8 million individuals (out of a private household population of approximately 57 million individuals) have incomes above $£ 1,100$ a week. The graph also shows that there are approximately half a million individuals whose income is between zero and $£ 10$ a week. Such a discontinuity in the distribution arises because negative incomes have been set to zero. In the data, we observe close to 500,000 individuals who have zero or negative income, which could be due to factors such as large self-employment losses or because of various payments that are deducted when calculating total income.

\footnotetext{
${ }^{4}$ Mean income is obtained by adding up all incomes and dividing by the total number of people in the population. It gives equal weight to all observations and can therefore be quite sensitive to very low and very high incomes. In contrast, the median is a measure of average that divides the population into two equally sized groups. Half the population have incomes below the median and half have incomes above it. The median is not affected by the presence of very high and very low incomes in the distribution. It is because of the potential differences in these measures of average that it is useful to consider both.

${ }^{5}$ Here, and throughout this section, we focus on income before housing costs have been deducted.
} 
Figure 1. The income distribution in 2005-06 (UK)

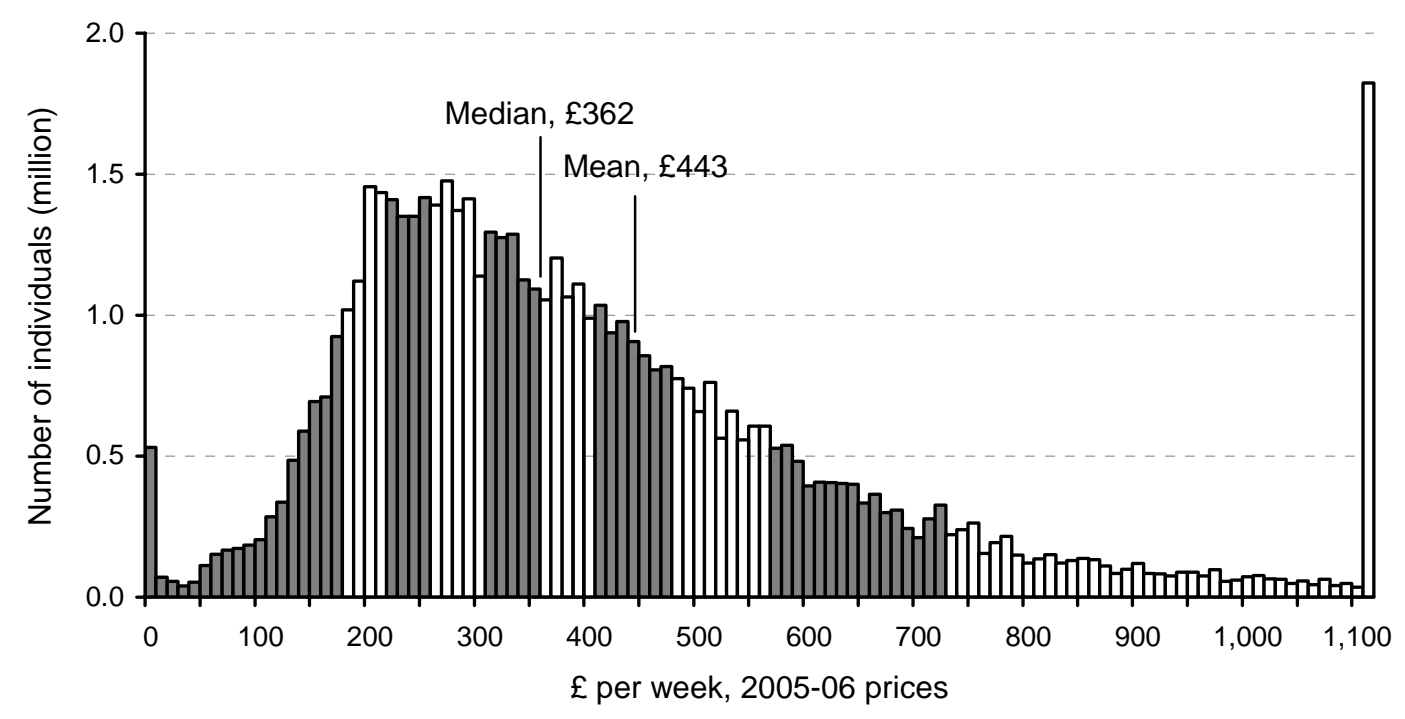

Notes: Incomes have been measured before housing costs have been deducted. The rightmost bar represents incomes of over $£ 1,100$.

Source: Authors' calculations using Family Resources Survey, 2005-06.

Figure 1 also divides the population into 10 equally sized groups, called decile groups. The first decile group contains the poorest $10 \%$ of the population, the second decile group contains the next poorest $10 \%$, and so on. In the graph, the alternately shaded sections represent these different decile groups, and, as can be seen, the distribution is particularly concentrated within a fairly narrow range of incomes in decile groups 2 to 5 . However, as we move further up the income distribution, a widening of the decile group bands can be seen. Note that the tenth decile group band is much wider than is shown in Figure 1 because those with incomes greater than $£ 1,100$ are shown together rather than in $£ 10$ bands.

Figure 2 shows how the income distribution has changed between 1996-97 and 2005-06. From now on, the focus will be on Great Britain rather than the United Kingdom, in order to allow us to make consistent comparisons of income distributions over time.

The first two panels of Figure 2 repeat the type of presentation used in Figure 1 , showing the number of people in various income bands in each year. The third panel allows us to see more clearly how the shape of the income distribution has changed over time, by comparing 'kernel density' estimates of the shapes of the distributions. The units for these kernel density estimates are 
Figure 2. The income distributions in 1996-97 and 2005-06 compared (GB)
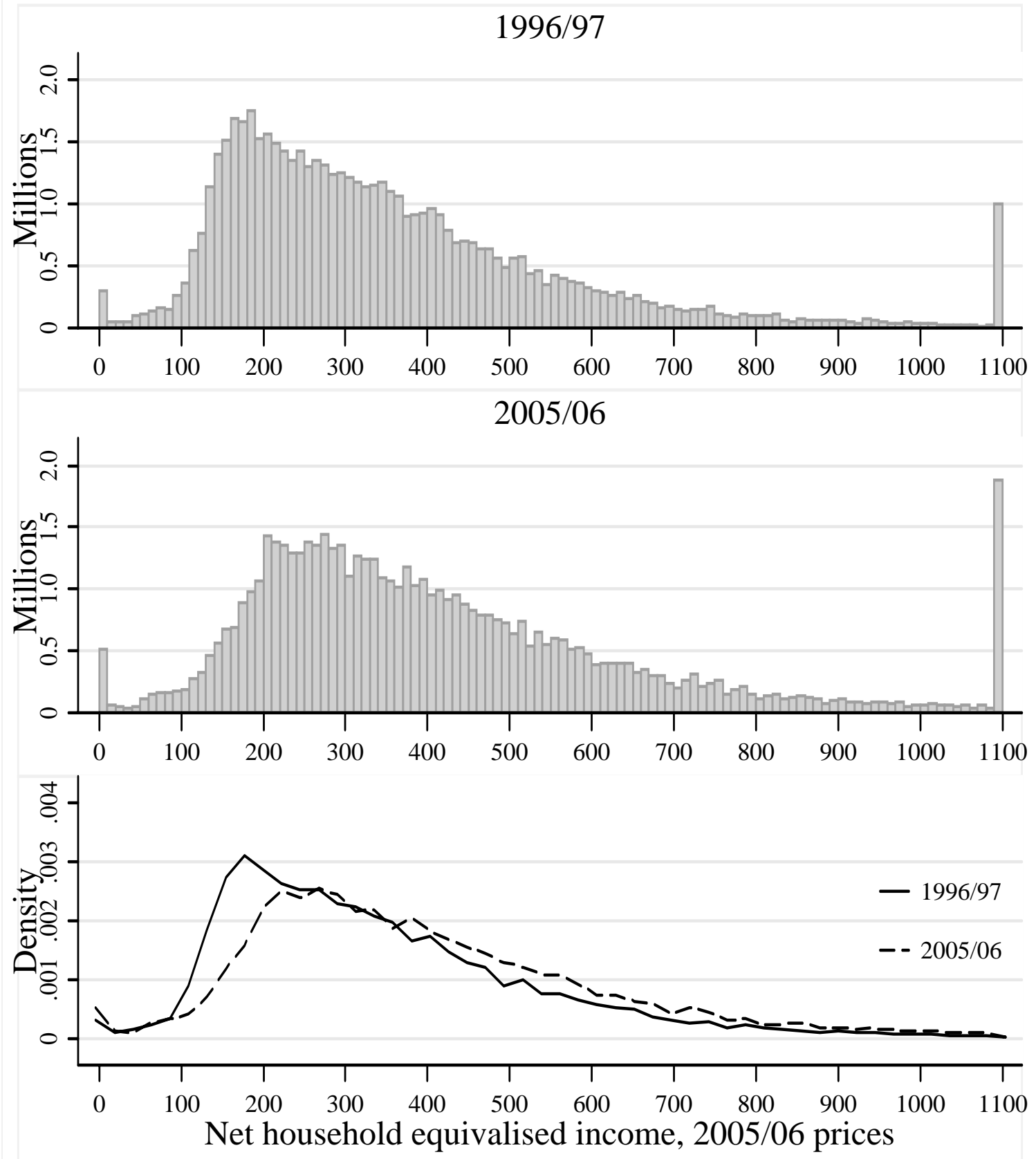

Notes: Incomes have been measured before housing costs have been deducted. The rightmost bar in the top two panels represents incomes of over $£ 1,100$.

Source: Authors' calculations using Family Resources Survey, 1996-97 and 2005-06.

such that the total area under each plotted line is 1 rather than the size of the total population. Looking at this lowest panel, comparing 1996-97 with 200506, the shape of the Great Britain income distribution appears to have changed. First, there has been a rightward shift as a result of general growth in households' incomes. Second, the income distribution appears to have become 
somewhat flatter, with a less pronounced spike at the modal income. ${ }^{6}$ Looking at the top two panels, it can be seen that a greater number of individuals fall into the highest income band in 2005-06 than in 1996-97.

\subsection{Changes in mean and median income}

Trends in average (mean and median) incomes, and the real percentage change in mean income in each year, since 1979 are shown in Figure 3. The graph shows that over this period, average incomes have tended to rise, though the rate of growth has not been constant over time. Since 1996-97, mean weekly BHC income in Great Britain has increased from $£ 363$ in 1996-97 to $£ 445$ in 2005-06. This corresponds to a real rise of around $22 \%$, or $2.3 \%$ on an annualised basis. Similarly, median income increased by $20 \%$ (2.0\% when annualised), from $£ 303$ to $£ 363 .^{7}$

\section{Figure 3. Changes in average real incomes since 1979 (GB)}

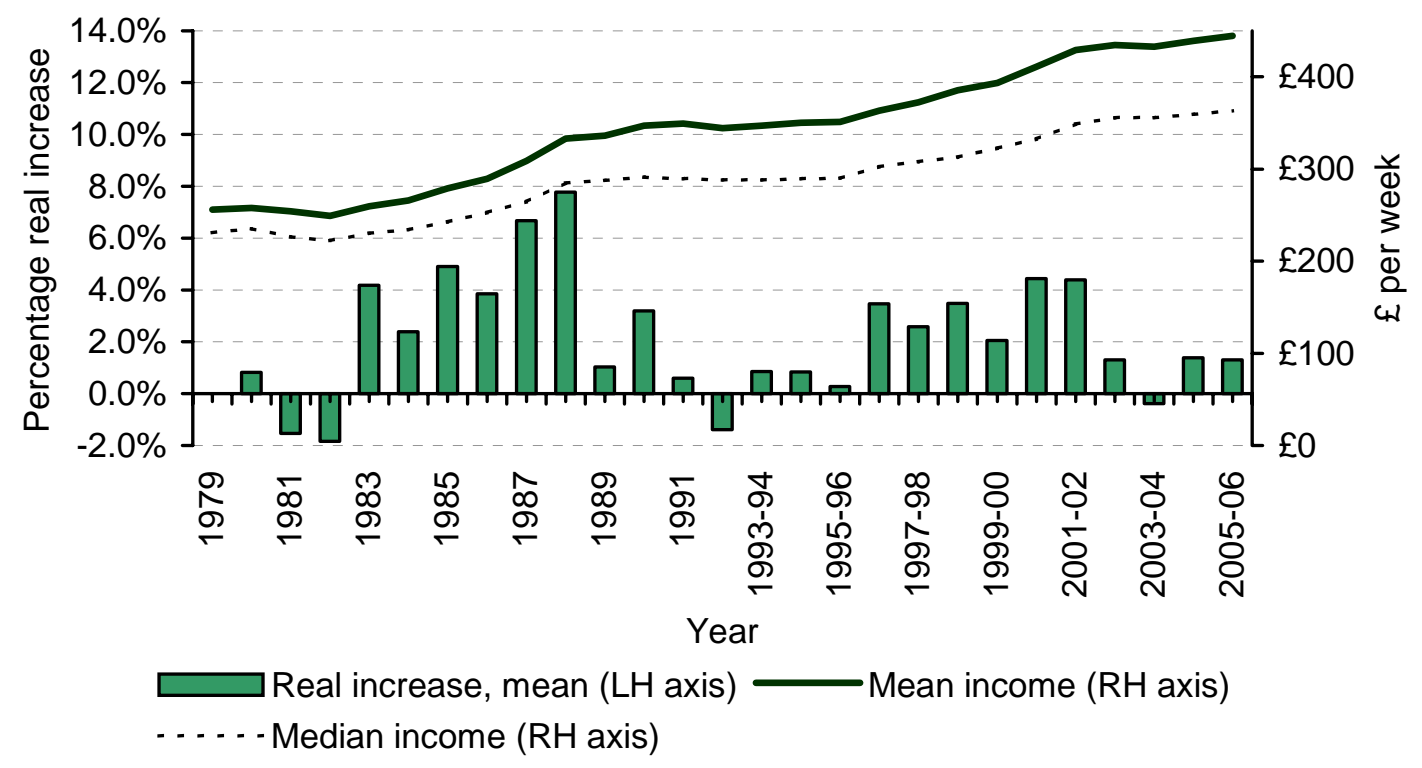

Note: Incomes have been measured before housing costs have been deducted.

Source: Authors' calculations using Family Expenditure Survey and Family Resources Survey, various years.

\footnotetext{
${ }^{6}$ Modal income refers to the income level possessed by the greatest proportion of the population.

${ }^{7}$ The growth of income is slightly stronger when measured AHC rather than BHC: mean and median incomes increased by $31 \%$ and $28 \%$ respectively measured after housing costs, between 1996-97 and 2005-06.
} 
Table 1. Real income growth and 95\% confidence intervals (GB)

\begin{tabular}{l|ccc|ccc}
\hline & \multicolumn{3}{|c|}{ Mean income } & \multicolumn{3}{c}{ Median income } \\
& Lower & Point & Upper & Lower & Point & Upper \\
\hline $1997-98$ & $0.8 \%$ & $2.6 \%$ & $4.2 \%$ & $0.2 \%$ & $1.8 \%$ & $3.1 \%$ \\
$1998-99$ & $1.4 \%$ & $3.5 \%$ & $5.5 \%$ & $0.2 \%$ & $1.5 \%$ & $2.9 \%$ \\
$1999-00$ & $0.1 \%$ & $2.1 \%$ & $4.2 \%$ & $1.6 \%$ & $3.1 \%$ & $4.6 \%$ \\
$2000-01$ & $2.4 \%$ & $4.4 \%$ & $6.7 \%$ & $1.7 \%$ & $3.1 \%$ & $4.8 \%$ \\
$2001-02$ & $2.5 \%$ & $4.4 \%$ & $6.7 \%$ & $3.4 \%$ & $4.9 \%$ & $6.2 \%$ \\
\hline $2002-03$ & $-0.8 \%$ & $1.3 \%$ & $3.5 \%$ & $0.8 \%$ & $2.0 \%$ & $3.4 \%$ \\
$2003-04$ & $-2.4 \%$ & $-0.4 \%$ & $1.7 \%$ & $-1.1 \%$ & $0.0 \%$ & $1.3 \%$ \\
$2004-05$ & $-0.7 \%$ & $1.4 \%$ & $3.5 \%$ & $-0.1 \%$ & $1.0 \%$ & $2.2 \%$ \\
$2005-06$ & $-0.7 \%$ & $1.3 \%$ & $3.4 \%$ & $-0.4 \%$ & $1.0 \%$ & $2.2 \%$ \\
\hline
\end{tabular}

Note: Incomes have been measured before housing costs have been deducted.

Source: Authors' calculations using Family Resources Survey, various years.

The real percentage changes in mean and median incomes taking in each year since 1996-97 are shown in Table 1, together with the 95\% confidence intervals for these changes. The table shows that in the last year of the data, mean income rose by $1.3 \%$ in real terms (or the equivalent of around $£ 6$ per week for a couple with no children), while median income rose in real terms by $1 \%$ (by around $£ 3$ per week). Neither of these changes is statistically significantly different from zero. ${ }^{8}$ It is noticeable that the annual growth in mean and median incomes has been markedly slower over the last four years (since 2002-03) than in earlier years of the Labour government.

We can also put this recent income growth into context, by comparing growth across periods of time defined by political events. In making these comparisons, it is important to realise that these periods cover different stages of various economic cycles, and income growth rates are very sensitive to this.

Bearing this in mind, we can see from Table 2 that average income growth under the period of the Labour government as a whole has been roughly comparable to the average annualised income growth under the Conservative governments between 1979 and 1996-97, though somewhat stronger than it was under Major and slightly slower than that experienced under Thatcher. Table 2 also shows income growth for Blair's first and second terms in office, and in the last year of the official data (i.e. between 2004-05 and 2005-06).

\footnotetext{
${ }^{8}$ The mean and median income changes between 2004-05 and 2005-06 are not statistically significant; however, the increase between 2003-04 and 2005-06 in both the mean and median is statistically significant.
} 
Average incomes, measured by both the mean and the median, clearly grew faster in the first parliament than in the second parliament of the Labour government (and indeed the fastest income growth in the second parliament actually occurred in the very first year of the second parliament, i.e. between 2000-01 and 2001-02).

Table 2. Annualised real average income growth (GB)

\begin{tabular}{l|cc}
\hline & Mean & Median \\
\hline $\begin{array}{l}\text { Conservatives (1979 to 1996-97) } \\
\text { Of which }\end{array}$ & $\mathbf{2 . 1 \%}$ & $\mathbf{1 . 6 \%}$ \\
Major (1990 to 1996-97) & $0.8 \%$ & $0.6 \%$ \\
Thatcher (1979 to 1990) & $2.8 \%$ & $2.1 \%$ \\
& & \\
Labour (1996-97 to 2005-06) & $\mathbf{2 . 3 \%}$ & $\mathbf{2 . 0 \%}$ \\
Of which & & \\
Blair I (1996-97 to 2000-01) & $3.1 \%$ & $2.4 \%$ \\
Blair II (2000-01 to 2004-05) & $1.7 \%$ & $2.0 \%$ \\
2004-05 to 2005-06 & $1.3 \%$ & $1.0 \%$ \\
\hline
\end{tabular}

Note: Incomes have been measured before housing costs have been deducted.

Source: Authors' calculations using Family Resources Survey and Family Expenditure Survey, various years.

It is interesting to place this relatively slow growth in average income in recent years in the context of the changes occurring in other countries. In particular, considerable attention has recently been placed on what has been happening to middle incomes in the US, where it has been noted that the real weekly wage of the median worker has been falling in real terms in recent years. ${ }^{9}$ Our analysis here relates to household income from all sources, measured after taxes and adjusted for household size, and so is not directly comparable to these findings. However, we can see that although there has been a slowing of the rate of growth in the median income in recent years, there is no sign of falling incomes in the middle of the distribution to date.

In order to start to explain what factors lie behind the relatively slower growth in mean and median incomes in recent years that was highlighted in Tables 1 and 2 and Figure 3, Table 3 shows what has happened to the mean values of the sources of income making up household income, both in the last year and over Labour's period of government. The first row of the table shows that by far the biggest source of household income, across the whole population, is income

\footnotetext{
${ }^{9}$ See 'Many workers are missing out on the rewards of globalization', The Economist, 14 September 2006.
} 
from earnings, followed by income from state benefits and tax credits, selfemployment income, and income from savings, investments and private pensions. The relatively slow growth in mean income in the last year reflects the growth in the mean value of most income sources, including earnings, state benefits and tax credits, and self-employment income. Mitigating this is a relatively higher growth in income from savings, investments and private pensions, and an overall real reduction in the value of payments that are deducted from income (the most significant of which is council tax). It should be noted that council tax rose by $1.3 \%$ in real terms between $2004-05$ and 2005-06, the smallest real rise seen during the current government's time in office (following the decision in the 2004 Pre-Budget Report to give local authorities an additional $£ 150$ million in 2005-06).

Table 3. Income sources: real year-on-year income growth and share of total income (GB)

\begin{tabular}{|c|c|c|c|c|c|c|c|c|}
\hline & \multicolumn{4}{|c|}{ Source of income } & & & TOTAL & TOTAL \\
\hline & Earnings & $\begin{array}{l}\text { Benefits } \\
\text { and tax } \\
\text { credits }\end{array}$ & $\begin{array}{c}\text { Self- } \\
\text { employ- } \\
\text { ment }\end{array}$ & $\begin{array}{c}\text { Savings, } \\
\text { investment, } \\
\text { private } \\
\text { pensions }\end{array}$ & Other & Payments & & $\begin{array}{l}\text { HBAI } \\
\text { income }\end{array}$ \\
\hline Share of total income: & & & & & & & & \\
\hline $2005-06$ & $66 \%$ & $19 \%$ & $10 \%$ & $10 \%$ & $3 \%$ & $-7 \%$ & $100 \%$ & $\mathrm{n} / \mathrm{a}$ \\
\hline Annual change: & & & & & & & & \\
\hline $2004-05$ to $2005-06$ & $1.4 \%$ & $1.3 \%$ & $0.0 \%$ & $2.9 \%$ & $0.6 \%$ & $-3.3 \%$ & $1.7 \%$ & $1.3 \%$ \\
\hline $1996-97$ to $2005-06$ & $2.8 \%$ & $1.8 \%$ & $1.6 \%$ & $1.6 \%$ & $4 \%$ & $6.6 \%$ & $2.1 \%$ & $2.3 \%$ \\
\hline
\end{tabular}

Notes: All sources of income have been equivalised and are measured at the household level.

The sum of all income sources is not exactly equal to household income under the HBAI definition, for two reasons. First, the incomes of the very richest households are adjusted within the HBAI definition to take into account potential under-sampling or inaccurate reporting of income at the very top of the income distribution (the so-called 'SPI adjustment'). No such SPI adjustment is attempted on the individual sources of income. Second, negative household incomes are set to zero within the HBAI definition of income, but the component income sources have not been adjusted in this way.

The final two columns of this table show how the year-on-year change in mean income on the HBAI definition ('TOTAL HBAI income') compares with the change in the mean of the total of all income sources ('TOTAL').

How much were reforms to taxes and benefits that directly affected incomes in 2005-06 responsible for the changes in mean and median incomes observed? These reforms included uprating of both the per-child element of the child tax credit and the pension credit guarantee in line with earnings, increases to the maximum childcare support within the childcare element of the working tax 
credit, and changes to the one-off payments given to pensioners alongside winter fuel allowances. Our simulations suggest that while, overall, the reforms directly affecting incomes in that year represented a small net giveaway to the household sector, they had little overall impact on the mean and median incomes: without the reforms, mean and median income growth would have been approximately 0.2 percentage points lower (making a difference of about 70p to mean income). This contrasts with some previous years (e.g. 2003-04), when fiscal reforms played a significant role in slowing the growth of average net income.

Box 3. Incomes, taxes, and tax and benefit reforms

This box brings together and summarises IFS analysis on how average incomes have changed since 1996-97, how tax and benefit reforms have affected average income, and what has happened to tax revenues over Labour's time in government.

- Mean household disposable income has risen in real terms by around $22 \%$ between $1996-97$ and $2005-06$, or $2.3 \%$ on an annualised basis. Median income increased by $20 \%$, or $2.0 \%$ when annualised.

- Looking just at the effects on household incomes of tax, benefit, and tax credit reforms implemented by Labour governments since 1997, IFS analysis suggests that they have resulted in a net revenue increase. In total, fiscal reforms from all of Labour's Budgets up to Budget 2007 have reduced mean household disposable income by $£ 2.28$ a week or $0.4 \%$. Taking into account above-inflation increases in council tax since 1997 leaves households overall $£ 5.90$ a week worse off, representing 1.1\% of income. See IFS Post-Budget Briefing 2007 for more information on the distributional effect of Labour's reforms. ${ }^{a}$

- Tax revenues have gone up considerably: total current receipts increased from $37.3 \%$ of GDP in 1996-97 to an expected $40.1 \%$ in $2007-08$. This is the equivalent of an increase in tax payments of approximately $£ 1,300$ per family in 2007-08 prices. Around $70 \%$ of this increase is due to discretionary reforms to taxes and benefits, with the rest due to changes in the economy. ${ }^{\text {b }}$

${ }^{a} \mathrm{M}$. Brewer, 'Winners and losers from personal and indirect tax changes', IFS Post-Budget Briefing 2007 (http://www.ifs.org.uk/budgets/budget2007/distribution.ppt).

${ }^{\mathrm{b}}$ Update of table 2.1 in R. Chote, C. Emmerson, A. Leicester and D. Miles (eds), The IFS Green Budget 2007, Commentary no. 102, IFS, London, 2007

(http://www.ifs.org.uk/publications.php?publication id=3841), using Budget 2007.

Appendix 1 shows how the changes to average incomes measured in HBAI compare with other survey-based measures and with measures from the National Accounts. All the measures we consider show a very similar pattern of change in mean income since 1996-97, and a marked slowdown in average income growth from 2002-03 onwards. 


\section{Inequality}

In the last section, we considered changes in average incomes. Here, we consider how equally (or otherwise) incomes are distributed, and how the degree of inequality has changed over the last year of data and under Labour's time in government. In our discussions of inequality, we will be adopting a relative notion of inequality. This means that should all incomes increase or decrease by the same proportional amount, we would conclude that income inequality had remained unchanged.

\subsection{Income changes by quintile group}

One common way to show how inequality has changed across the population is to consider average real income growth by quintile group (each quintile group contains $20 \%$ of the population, or around 11 million individuals).

As discussed in Section 2.2, between 2004-05 and 2005-06 mean and median income grew in real terms by $1.3 \%$ and $1.0 \%$ respectively. Figure 4 shows the underlying pattern of this income growth by quintile group. It shows an unequal distribution, with the individual in the middle of the poorest fifth of the population typically seeing a slight, statistically insignificant fall in income in the last year, and successive income quintiles seeing successively stronger income growth. Though the magnitude of these changes is small, they imply if anything a small increase in overall income inequality in the last year, a point to which we will return when we consider recent changes in some summary measures of inequality, in Section 3.3.

Figure 4. Real income growth by quintile group, 2004-05 to 2005-06 (GB)

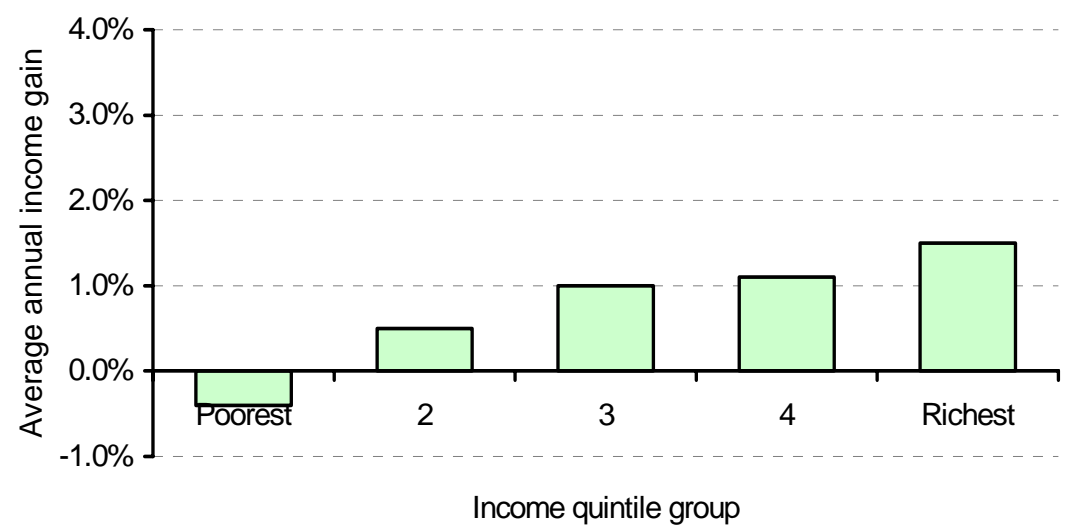

Notes: The averages in each quintile group correspond to the midpoints, i.e. the $10^{\text {th }}, 30^{\text {th }}$, $50^{\text {th }}, 70^{\text {th }}$ and $90^{\text {th }}$ percentile points of the income distribution. Incomes have been measured before housing costs have been deducted.

Source: Authors' calculations using Family Resources Survey, 2004-05 and 2005-06. 
Figure 5. Real income growth by quintile group (GB)

Blair: 1996-97 to 2005-06

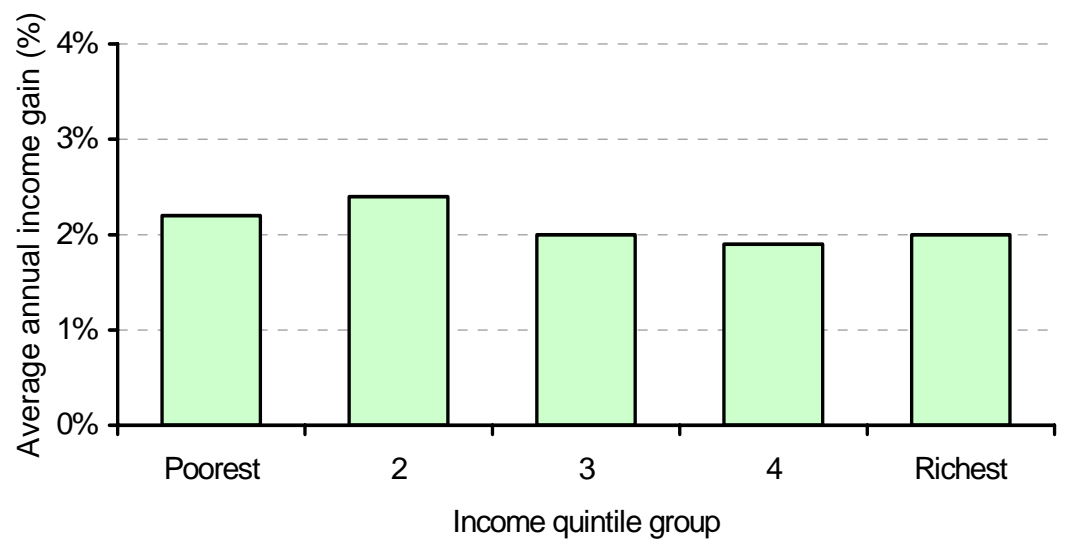

Conservatives: 1979 to $1996-97$

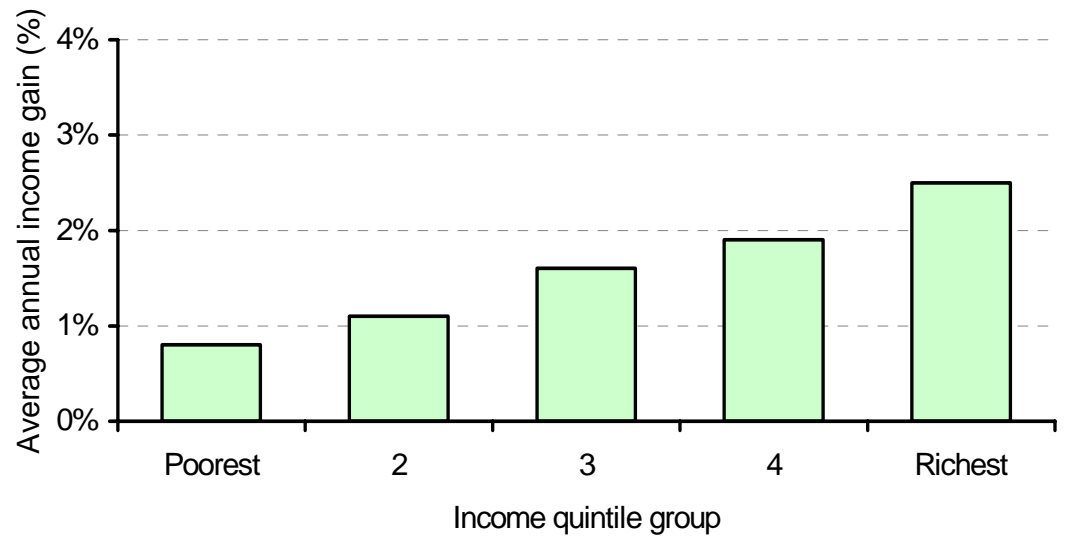

Notes: The averages in each quintile group correspond to the midpoints, i.e. the $10^{\text {th }}, 30^{\text {th }}$, $50^{\text {th }}, 70^{\text {th }}$ and $90^{\text {th }}$ percentile points of the income distribution. Incomes have been measured before housing costs have been deducted.

Source: Authors' calculations using Family Resources Survey and Family Expenditure Survey, various years.

Figure 5 looks at the changes over time as defined by political eras, showing how changes under the Labour government compare with what happened under the Conservatives between 1979 and 1996-97. It is important to remember again that the pattern of income growth is strongly influenced by booms and recessions, and that our comparisons across periods of government cover different stages of various economic cycles and will be affected by this.

Taking the period 1996-97 to 2005-06 as a whole, all quintile groups have experienced income growth in the region of $1.9 \%-2.4 \%$ on an annualised basis. The second quintile group fared best, with annual income growth of $2.4 \%$, but there is relatively little difference across quintile groups. This pattern taken alone would suggest little change in income inequality over Labour's time in 
government, again a point to which we will return in Section 3.3. This is very different from what happened under the previous Conservative governments, when over the period as a whole, income growth was stronger the richer the quintile group, a pattern consistent with strongly rising inequality. Interestingly, the pattern of income change over the last year shown in Figure 4 is more similar to the pattern over the Conservative era than to the cumulative changes under Labour.

Table 4 gives income growth by quintile separately for each of Labour's terms in office and also divides the Conservative era into the premierships of Thatcher and Major. It shows that during Labour's first term, the second and top quintiles experienced the fastest income growth (2.7\% annualised). In contrast, income grew faster for poorer quintiles than for richer ones during Labour's second term: income among the poorest quintile grew by $2.6 \%$ annualised, compared with $1.4 \%$ for the richest quintile.

Table 4. Real income growth by quintile group, across parliaments and between 2004-05 and 2005-06 (GB)

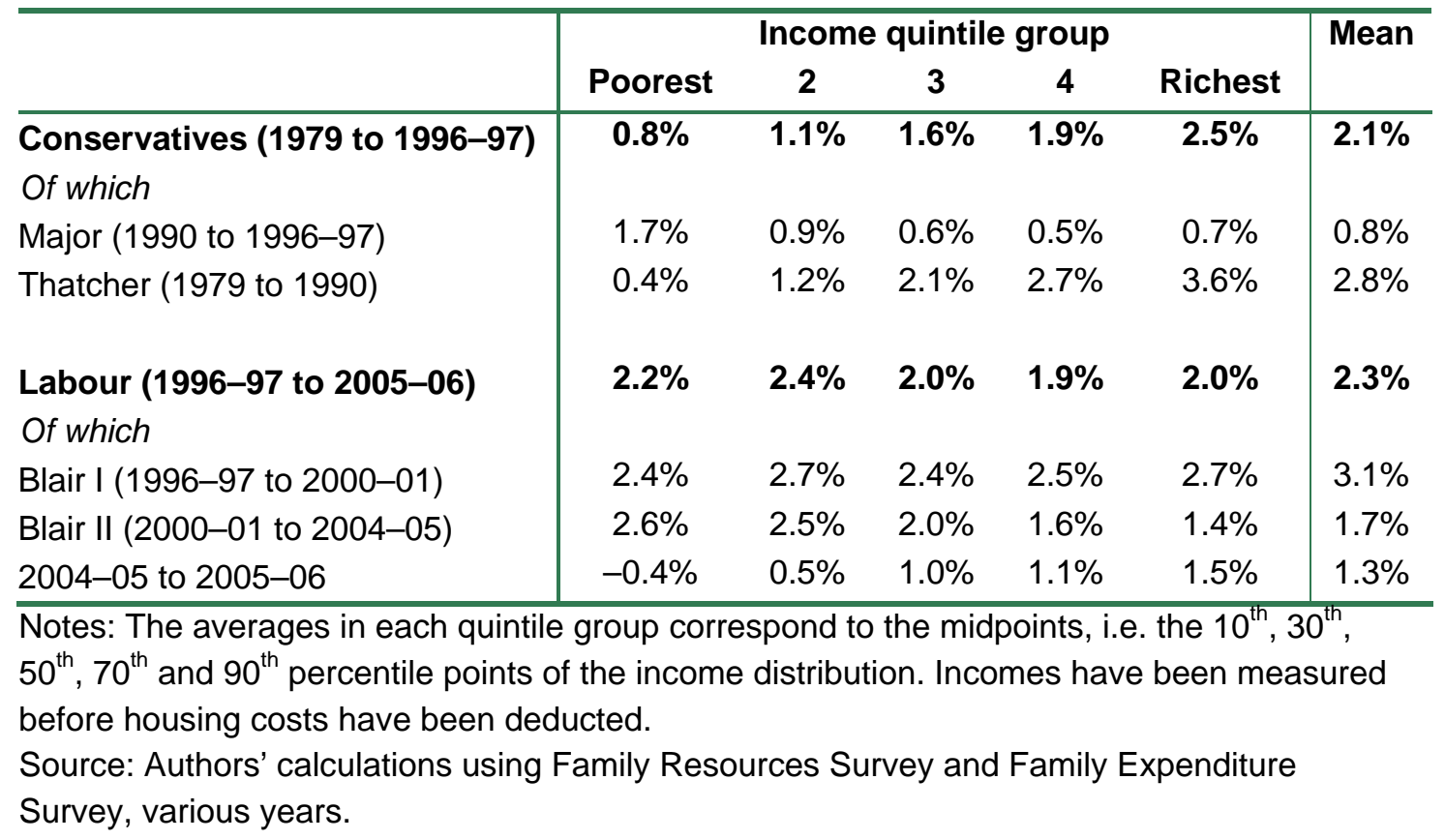

\subsection{Income changes by percentile}

While Figures 4 and 5 give us a reasonable impression of how incomes have been changing across much of the distribution, they do mask the changes at the extremes. In Figure 6, we show how incomes in Great Britain have changed right across the distribution between 2004-05 and 2005-06 - including those 
individuals at the $99^{\text {th }}$ percentile point. This graph is similar to the 'quintile' chart in Figure 4, except that rather than presenting how incomes have changed in different quintile groups, we instead consider income growth at 99 percentile points in the income distribution. ${ }^{10}$ In order to highlight the large degree of statistical uncertainty behind the estimated real change in income at each percentile point, we also show the $95 \%$ confidence intervals for these changes, which in all cases are very wide, but they are particularly wide at the lower and upper ends of the distribution. The graph shows that income growth has been rather uneven across the distribution but appears to be generally lower in the bottom half of the income distribution than in the top half.

Figure 6. Real income growth by percentile point, 2004-05 to 2005-06 (GB)

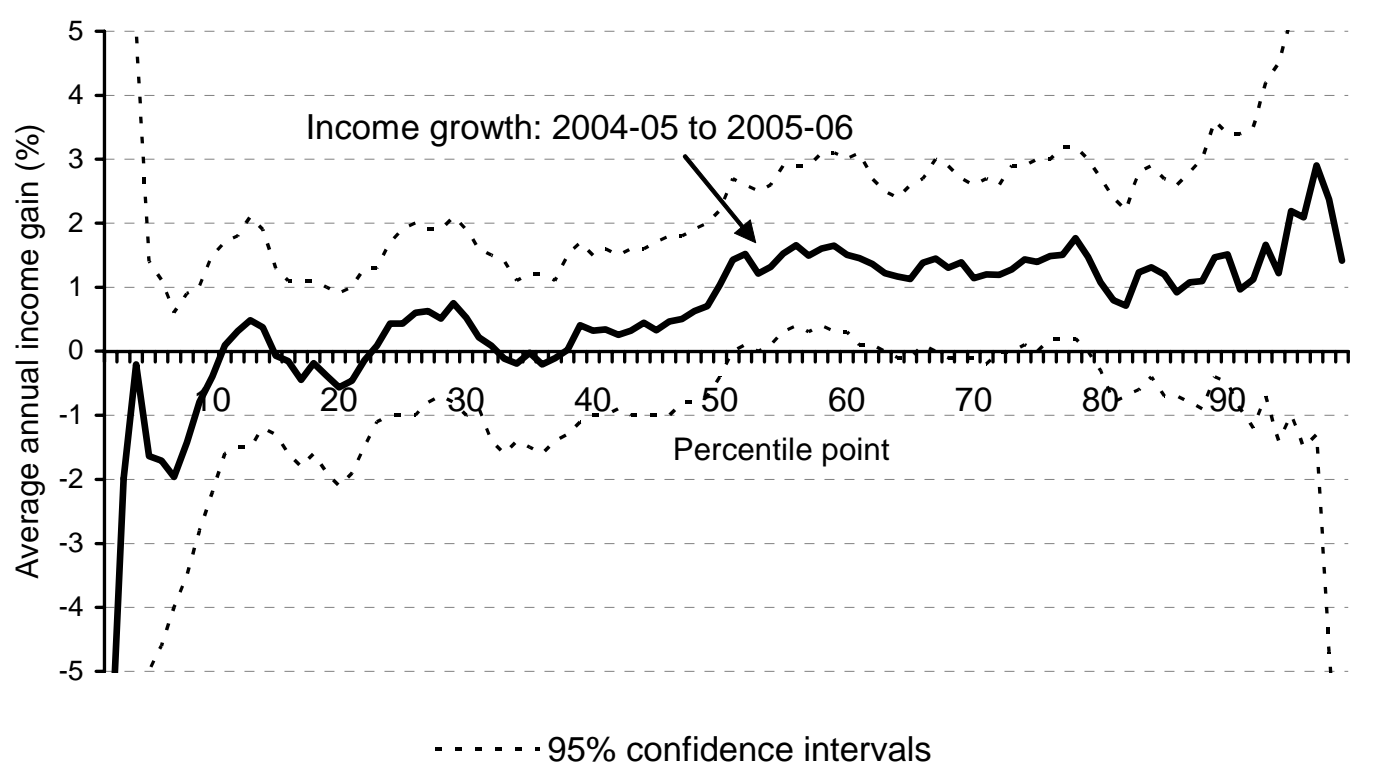

Notes: The change in income at the $1^{\text {st }}$ percentile is not shown on this graph. Incomes have been measured before housing costs have been deducted.

Source: Authors' calculations using Family Resources Survey, 2004-05 and 2005-06.

Figure 7 takes the period of the Labour government as a whole, showing how incomes have changed across the distribution. The differently shaded sections correspond to the different income decile groups. To place the changes in a historical context, we also show how this income growth compares with what was observed between 1979 and 1996-97 under the Conservative governments of this time, as illustrated by the superimposed line.

\footnotetext{
${ }^{10}$ In Figure 6, growth at the $1^{\text {st }}$ percentile point has not been shown, in order to maintain a reasonable scale for the graph.
} 
Figure 7. Real income growth by percentile point, 1996-97 to 2005-06 (GB)

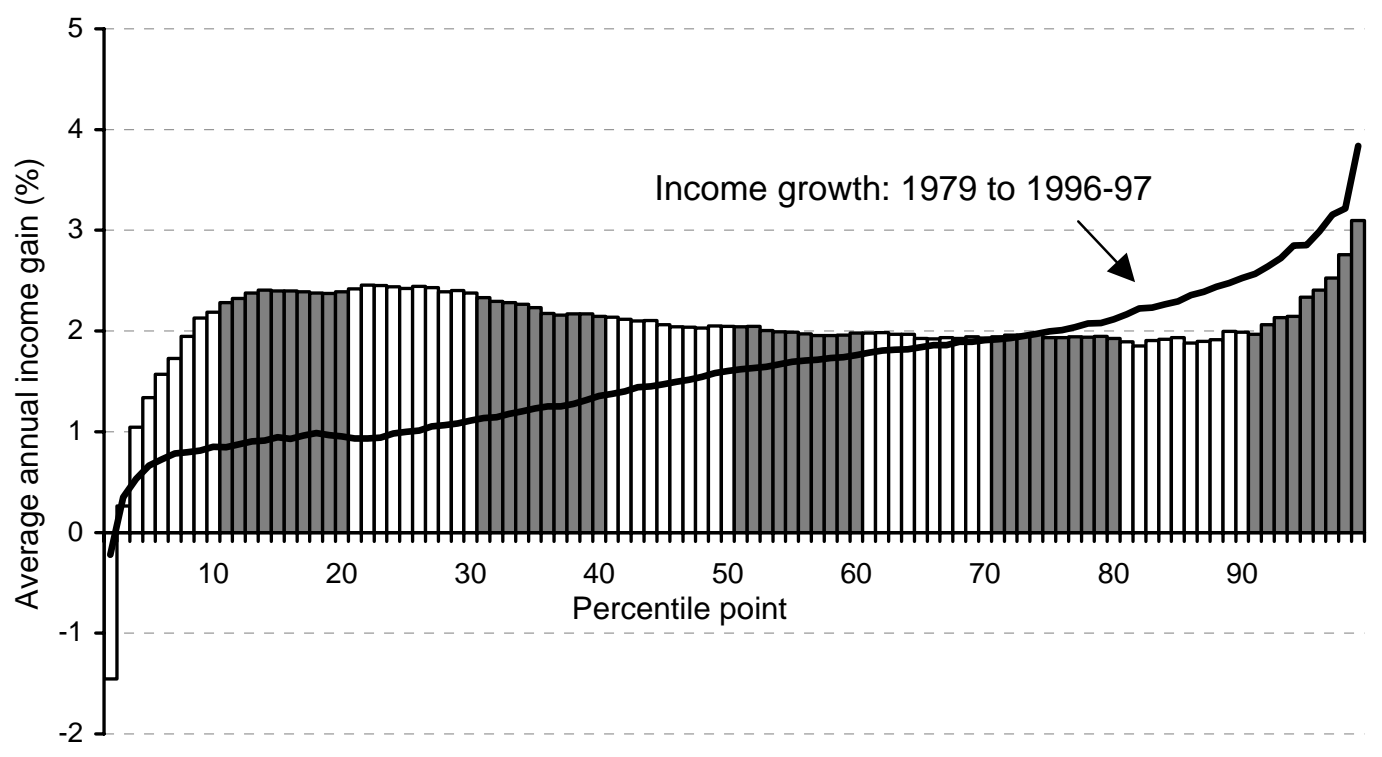

Notes: The change in income at the $1^{\text {st }}$ percentile is not shown on this graph. Incomes have been measured before housing costs have been deducted.

Source: Authors' calculations using Family Resources Survey and Family Expenditure Survey, various years.

Looking at the main bulk of the income distribution, we see that between about the $15^{\text {th }}$ percentile point and the $90^{\text {th }}$ percentile point, it is generally the lower parts of the distribution that have gained most over the period 1996-97 to 2005-06; by itself, this would be consistent with falling inequality. Below the $15^{\text {th }}$ percentile point, however, income growth is progressively lower the lower the income percentile, with real income falls in the very lowest part of the income distribution. Beyond the $90^{\text {th }}$ percentile point, income growth is generally increasing in income, with a spike at the $99^{\text {th }}$ percentile point. In previous years, we have pointed to the growth in the very top incomes as one driver of continued income inequality growth in recent years (e.g. see Brewer et al. $\left.(2006)^{11}\right)$.

The superimposed line in Figure 7 shows that almost without exception over the period 1979 to 1996-97, income growth was increasing in the level of income. The graph also shows that compared with the period of Conservative government as a whole, the first seven income deciles have seen stronger

\footnotetext{
${ }^{11}$ M. Brewer, A. Goodman, J. Shaw and L. Sibieta, Poverty and Inequality in Britain: 2006, Commentary no. 101, IFS, London, 2006 (http://www.ifs.org.uk/comms/comm101.pdf).
} 
annual average income growth under the Labour government, whilst income growth among the top three income deciles has been slightly lower.

While Figure 7 gives us a very detailed impression of how incomes have changed between specific years, it can also prove very useful to construct some summary measures of how inequality has evolved over time. Various measures are discussed in the next subsection.

\subsection{Summary measures of inequality}

\section{The Gini coefficient}

The Gini coefficient is a popular measure of income inequality that condenses the entire income distribution into a single number between zero and one: the higher the number, the greater the degree of income inequality. A value of zero corresponds to the absence of inequality, so that having adjusted for household size and composition, all individuals have the same household income. In contrast, a value of one corresponds to inequality in its most extreme form, with a single individual having command over the entire income in the economy. ${ }^{12}$ See appendix C of Brewer et al. (2006) ${ }^{13}$ for more information about the Gini coefficient.

Figure 8 shows the evolution of the Gini coefficient since 1979. Inequality rose dramatically over the 1980s, with the Gini rising from a value of around 0.25 in 1979 and reaching a peak in the early 1990s of around 0.34. The scale of this rise in inequality has been shown elsewhere ${ }^{14}$ to be unparalleled both historically and compared with the changes taking place at the same time in most other developed countries.

Since the early 1990s, the changes in income inequality have been less dramatic. After falling slightly over the early to mid-1990s, inequality rose again during Labour's first term, with the Gini coefficient reaching a new peak

\footnotetext{
${ }^{12}$ Note that the Gini coefficient can be interpreted as the expected proportional income gap between two individuals randomly selected from the population (normalised by twice the mean).

${ }^{13}$ M. Brewer, A. Goodman, J. Shaw and L. Sibieta, Poverty and Inequality in Britain: 2006, Commentary no. 101, IFS, London, 2006 (http://www.ifs.org.uk/comms/comm101.pdf).

${ }^{14}$ See A. Goodman, P. Johnson and S. Webb, Inequality in the UK, Oxford University Press, Oxford, 1997; P. Gottschalk and T. M. Smeeding, 'Cross-national comparisons of earnings and income inequality', Journal of Economic Literature, 1997, vol. 35, no. 2, pp. 633-87; and A. Atkinson, 'The distribution of income in the UK and OECD countries in the twentieth century', Oxford Review of Economic Policy, 1999, vol. 15, no. 4, pp. 56-75.
} 
of 0.35 in 2000-01. During Labour's second term, however, the Gini fell, with the level of inequality in 2004-05 returning to that last seen in 1997-98. Over the first two terms of the Labour government, the net effect of these changes was to leave income inequality effectively unchanged and at historically high levels.

Figure 8. The Gini coefficient, 1979 to 2005-06 (GB)

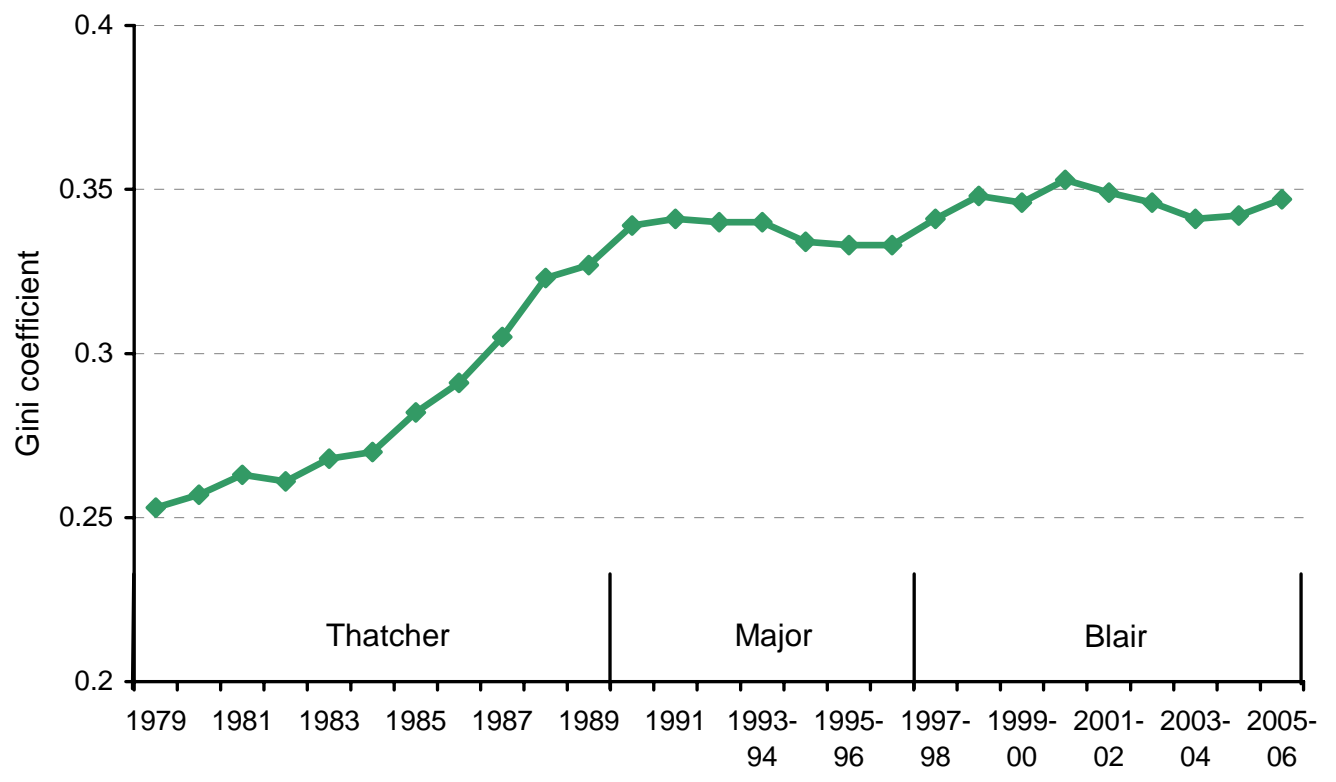

Note: The Gini coefficient has been calculated using incomes before housing costs have been deducted.

Source: Authors' calculations using Family Resources Survey and Family Expenditure Survey, various years.

The most recent year (between 2004-05 and 2005-06) has seen a small increase in the Gini coefficient again. Though this year-on-year change is small and not statistically significant, comparing the level of income inequality in 2005-06 with that inherited when Labour came to power in 1996-97 we find that the Gini coefficient was slightly higher ( 0.35 compared with 0.33 ) and that the increase over this period is statistically significant at the $5 \%$ level. ${ }^{15}$

Other summary measures of inequality

There are a wide range of other measures available to summarise income inequality, based on different definitions of income inequality.

\footnotetext{
${ }^{15}$ The Gini coefficient for 2004-05 is also higher than that for 1996-97, but this difference is not statistically significant.
} 
Focusing on the period since 1996-97, Figure 9 shows the path of a selection of inequality measures, indexed so as to equal 1 in 1996-97. The 90:10 ratio is the simplest of these measures, as it is just the ratio of the income of the household at the $90^{\text {th }}$ percentile point to that of the household at the $10^{\text {th }}$ percentile point. Mean log deviation (MLD) measures the expected percentage difference between the income of a randomly selected individual and overall mean income. The Atkinson measure allows one to choose a value for society's aversion to inequality, defining the amount that society considers it necessary to give to a 'poor' person, having taken a given amount of income from a 'rich' person, in order to keep overall social welfare the same. The value we have chosen for this parameter reflects a society that considers it necessary to give $£ 33$ to a 'poor' person, having taken $£ 100$ from a 'rich’ person, in order to keep overall social welfare the same (this is a relatively inequality-averse society). This measure was discussed in more detail in appendix $\mathrm{C}$ of Brewer et al. (2006). ${ }^{16}$

Figure 9. Summary measures of income inequality, 1996-97 to 2005-06 (GB)

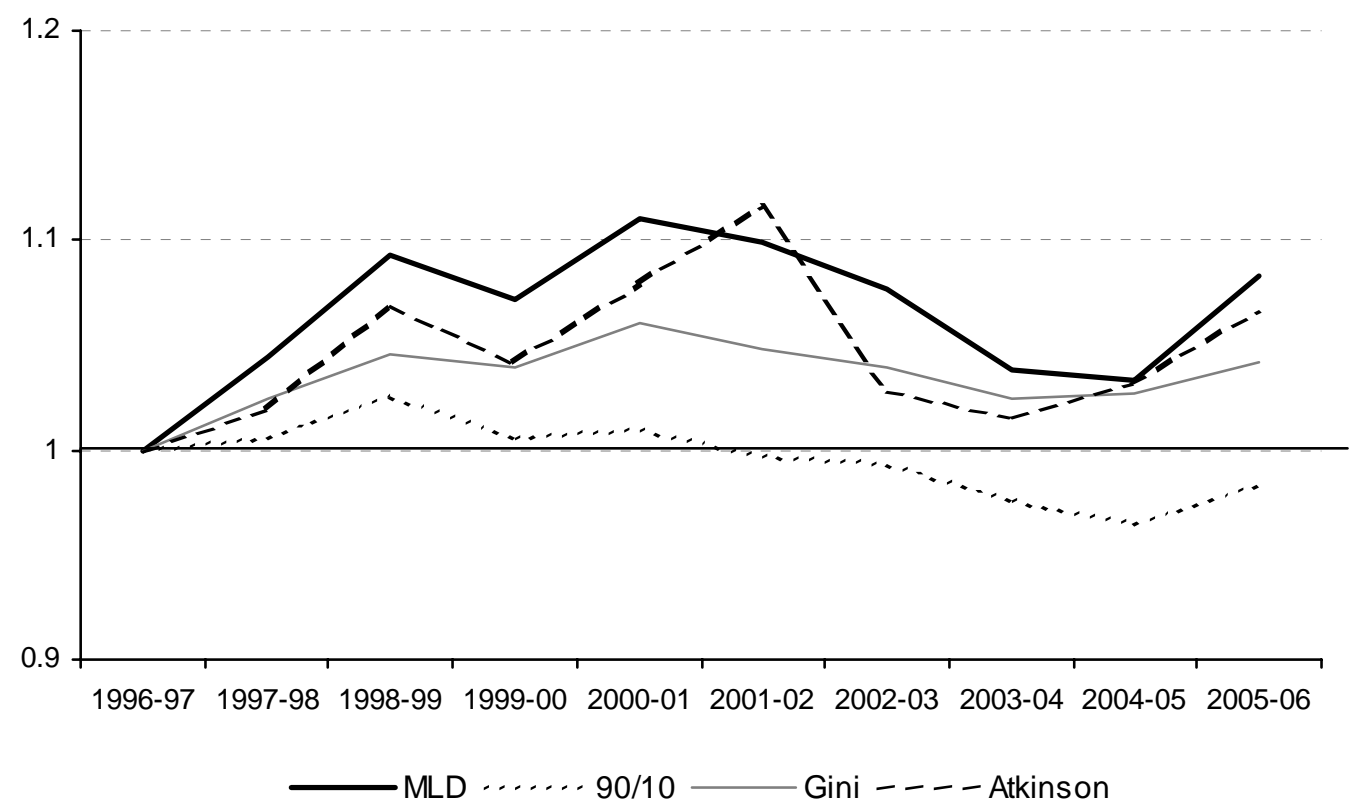

Notes: Measures have been calculated using incomes before housing costs have been deducted. The Atkinson inequality measure is shown for an inequality aversion parameter, $\varepsilon$, of 1.5. This implies that society considers it necessary to give $£ 33$ to a 'poor' person, having taken $£ 100$ from a 'rich' person, in order to keep overall social welfare the same. Source: Authors' calculations using Family Resources Survey, various years.

\footnotetext{
${ }^{16}$ M. Brewer, A. Goodman, J. Shaw and L. Sibieta, Poverty and Inequality in Britain: 2006, Commentary no. 101, IFS, London, 2006 (http://www.ifs.org.uk/comms/comm101.pdf).
} 
Figure 9 shows that all of these measures have ticked up in the last year, highlighting that the changes observed are consistent with a small, but in all cases statistically insignificant, rise in income inequality. This is the first year since 2000-01 that all these measures have risen at the same time.

Over a longer period of time, we can see from Figure 9 that inequality as measured by the Gini coefficient, MLD and Atkinson measure all rose throughout the later 1990s, rising most strongly according to MLD. They then fell back by 2004-05 to levels just above those seen in 1996-97.

The 90:10 ratio has seen a slightly different pattern, as it generally fell between 1998-99 and 2004-05 and thus was at a lower level in 2004-05 than it was in 1996-97. This different pattern compared with those of the other summary measures of inequality discussed above reflects the fact that the 90:10 ratio only captures the changes in income at two specific points in the income distribution - the $90^{\text {th }}$ and $10^{\text {th }}$ percentile points. Together with the pattern of change highlighted in Figure 7, one could conclude that it is the difference between income growth at the very bottom and very top of the distribution that is driving the slight rise in income inequality since 1996-97 as measured by the Gini coefficient, MLD and Atkinson measures. Stronger growth in the bottom deciles than the top deciles has led to a fall in income inequality as measured by the 90:10 ratio over several recent years. However, in the last year, the 90:10 ratio also rose slightly, returning the overall value to one very similar to that seen in 1996-97.

\subsection{Inequality and redistribution}

Labour has introduced a package of redistributive tax and benefit reforms since 1997. The IFS Post-Budget Briefing 2007 set out how fiscal reforms since 1997 have affected household incomes. It found that tax and benefit reforms since 1997 have clearly been progressive, benefiting the less-well-off relative to the better-off. ${ }^{17}$

Given the fact that Labour's tax and benefit reforms have tended to benefit poorer households at the expense of richer ones, it might seem surprising that income inequality is slightly higher on most measures than it was in 1996-97. To begin to understand why this is, we use the IFS tax and benefit model, TAXBEN, to calculate what incomes in 2005-06 would have been under the

\footnotetext{
${ }^{17} \mathrm{M}$. Brewer, 'Winners and losers from personal and indirect tax changes', IFS Post-Budget Briefing 2007 (http://www.ifs.org.uk/budgets/budget2007/distribution.ppt).
} 
April 1997 tax and benefit system, appropriately uprated. ${ }^{18}$ While the actual level of inequality as measured by the Gini coefficient is slightly higher in 2005-06 than it was nine years earlier, with an approximate value of 0.347 in 2005-06 compared with 0.333 in 1996-97, our simulations here suggest that the Gini coefficient would have increased considerably, to around 0.378 , if the tax and benefit system had remained unchanged. ${ }^{19}$ Our previous work has also tracked how the simulated 'no-policy-change' Gini coefficient would have evolved over time during each year of the Labour government; this has shown that from 1996-97 to 1999-2000, the tax and benefit reforms of the Labour government did little to affect inequality compared with what would have been observed if it had simply uprated the April 1997 system. However, since 200001, there has been a notable divergence between the actual pattern of inequality and the simulated pattern under the April 1997 system. This coincides with the introduction of large increases in means-tested benefits and tax credits, particularly those aimed at families with children and at pensioners. ${ }^{20}$

Although one explanation for this pattern could be rising inequality in the underlying distribution of income, this does not appear to have been the case. Goodman et al. (2005) ${ }^{21}$ and Jones (2006) ${ }^{22}$ show how the Gini coefficient for 'gross income' - that is, income before benefits and tax credits are added and

\footnotetext{
${ }^{18}$ In calculating these simulated incomes, individuals are awarded all benefits for which they appear eligible and no behavioural responses are allowed for. Because modelled incomes may differ from reported incomes under any observed tax and benefit system, calibration techniques are applied to the simulated income series. Only tax and benefit reforms directly affecting households are included in the simulation.

${ }^{19}$ Our estimate of inequality if the government had not made any tax and benefit changes has assumed that people's labour market behaviour does not depend on the tax and benefit system. This may, of course, not be true. If Labour's tax and benefit changes have induced behavioural changes that have acted to reduce inequality further, then we will be understating the extent to which Labour's changes have reduced inequality. In general, though, it is very hard to know whether any particular behavioural changes would act to reduce or increase inequality.
}

${ }^{20}$ See M. Brewer, A. Goodman, J. Shaw and A. Shephard, Living Standards, Inequality and Poverty, IFS Election Briefing Note no. 9, 2005 (http://www.ifs.org.uk/bns/05ebn9. pdf).

${ }^{21}$ A. Goodman, J. Shaw and A. Shephard, 'Understanding recent trends in income inequality', in S. Delorenzi, J. Reed and P. Robinson (eds), Maintaining Momentum: Promoting Social Mobility and Life Chances from Early Years to Adulthood, Institute for Public Policy Research, London, 2005.

${ }^{22}$ F. Jones, 'The effects of taxes and benefits on household income, 2004/05', Economic

Trends, May 2006, no. 630, pp. 53-98

(http://www.statistics.gov.uk/articles/economic trends/ET May Francis Jones.pdf). 
taxes deducted - has also remained at a fairly steady level over this period. This suggests that had the tax and benefit system remained unchanged since 1996-97, it would have become less redistributive over time, as a result of economic and demographic changes (such as falling unemployment).

We can also use simulation methods to assess whether the small observed rise in inequality in the last year of the data has been policy-driven. Tax and benefit reforms affecting incomes in 2005-06 appear to have had very little impact on overall levels of inequality, but what effect they had was to reduce inequality slightly: our simulations suggest that had the 2004-05 tax and benefit system remained in place in 2005-06, the Gini coefficient for net income would have been very slightly higher than actually observed, at 0.348 rather than the actual 0.347 .

\section{Poverty}

Reducing poverty amongst pensioners and families with children has formed an important part of the Labour government's agenda, particularly during its second term in office. In this section, we summarise the trends since 1996-97 in some of the government's main income-based poverty indicators, which are all derived from HBAI data.

In Section 4.1, we analyse recent changes in relative poverty for the population as a whole. Section 4.2 focuses on subgroups of the population, examining poverty amongst the government's favoured target groups of children and pensioners, and amongst working-age adults without dependent children. In both these sections, poverty is measured by counting the number of individuals whose household income is below $60 \%$ of that of the median individual (the median individual is in the middle of the income distribution). This is one of the measures against which the government will assess its progress towards achieving the relative poverty strand of its 2010-11 child poverty targets, and one of the indicators of poverty in Opportunity for All (OfA), ${ }^{23}$ the government's annual audit of poverty. The measure is a 'relative' measure of poverty because the poverty line moves with median income growth each year.

\footnotetext{
${ }^{23}$ Most recently, Department for Work and Pensions, Opportunity for All: Eighth Annual Report, Cm. 6915, TSO, London, 2006.
} 
Poverty rates can be measured using incomes before housing costs (BHC) or after housing costs (AHC). In OfA, the government presents relative poverty under both definitions, and we follow that practice here. However, for its child poverty target in 2010-11, the government has chosen to measure poverty using incomes measured BHC only. ${ }^{24}$

In Section 4.3, poverty is measured by counting the number of individuals whose household income is below 60\% of median income in 1996-97 (uprated for inflation). This is an 'absolute' measure of poverty because the poverty line is fixed in real terms, and it is the measure of absolute poverty presented in OfA. Note that the absolute strand of the child poverty target for 2010-11 measures absolute child poverty using as a poverty line $60 \%$ of the median income in 1998-99 (uprated for inflation). OfA also includes measures that count individuals with persistent low incomes, and a wide range of other indicators that are not income-based. We do not consider any of these here.

Box 4. UK or GB when comparing poverty rates?

In this section, most estimates of poverty are presented on a GB basis up to and including 2001-02 and on a UK basis in 2002-03 and subsequent years. The size of the discontinuity caused by the inclusion of Northern Ireland will depend on the number of low-income households in Northern Ireland and on the way that the median income changes, having added Northern Irish households, through its effect on the poverty line. In any case, the size of any discontinuity will be small: using a UK-wide poverty line, the risk of poverty in Northern Ireland in 2005-06 was 20.9\% measuring incomes $\mathrm{BHC}$, slightly higher than in the rest of the UK (17.5\%) (the opposite is true when measuring incomes AHC - 20.9\% in Northern Ireland compared with $21.7 \%$ in the rest of the UK); but only $2.9 \%$ of individuals in the UK live in Northern Ireland.

As noted in Section 1, figures here are presented on a GB basis up to and including 2001-02 and on a UK basis from 2002-03 (i.e. in the same way as they are presented in HBAI). Due to this break in the series, and because the size of populations can change over time, we will focus on trends in poverty measured by the fraction of individuals that it affects, rather than by the actual number of individuals. Nevertheless, most of the following tables present both the number of people who are poor and the percentage of the population they

\footnotetext{
${ }^{24}$ See M. Brewer, A. Goodman, J. Shaw and L. Sibieta, Poverty and Inequality in Britain: 2006, Commentary no. 101, IFS, London, 2006 (http://www.ifs.org.uk/comms/comm101.pdf).
} 
represent. We also report estimates of whether changes in poverty are statistically significant. $^{25}$

\subsection{The whole population}

There were 12.7 million individuals in relative poverty measuring incomes AHC and 10.4 million measuring them BHC in the UK in 2005-06, using a poverty line equal to $60 \%$ of median income. Both these numbers are higher than they were in 2004-05, by 600,000 (AHC) and 400,000 (BHC).

This rise in relative poverty is the first since 1996-97 (AHC) or 1997-98 (BHC), ending the longest decline in relative poverty since 1961 (the start of our consistent time series). Measuring incomes AHC, it is the largest annual rise in poverty since 1992. That poverty has risen is not a statistical artefact: relative poverty has risen across a wide range of poverty lines, measuring incomes both AHC and BHC, and the rise is statistically significantly different from zero on the majority of the poverty lines considered in this Briefing Note. ${ }^{26}$ The rise in relative poverty is a direct consequence of the relatively low growth in low incomes between 2004-05 and 2005-06 illustrated in Figure 6.

To give more perspective, Figure 10 shows relative poverty in Great Britain between 1979 and 2001-02 and in the UK from 2002-03 onwards, measuring incomes AHC (Figure 10a) and BHC (Figure 10b) and under a range of poverty lines. (Note that the rest of this section will tend to focus on poverty lines defined as $60 \%$ of median income.) One can see from these graphs that poverty rates measured after housing costs tend to be higher than those measured before housing costs, because those on low incomes tend to spend a greater proportion of their incomes on housing costs than those on high incomes.

Poverty rates increased dramatically during the 1980s, more slowly in the early 1990s and then stabilised or fell from the mid-1990s. But the latest year of data puts an end to the eight-year decline in relative poverty: between 2004-05 and

\footnotetext{
${ }^{25}$ These were calculated by bootstrapping the changes. This involves recalculating statistics for each of a series of random samples drawn from the original sample, as a way of approximating the distribution of statistics that would be calculated from different possible samples out of the underlying population. See A. C. C. Davison and D. V. Hinkley, Bootstrap Methods and their Application, Cambridge University Press, Cambridge, 1997.

${ }^{26}$ The changes are statistically significant with poverty lines set at $40 \%$ and $60 \%$ of median income $\mathrm{BHC}$ and at $50 \%, 60 \%$ and $70 \%$ of median income AHC.
} 
Figure 10a. Relative poverty: percentage of individuals in households with incomes below various fractions of median income (AHC)

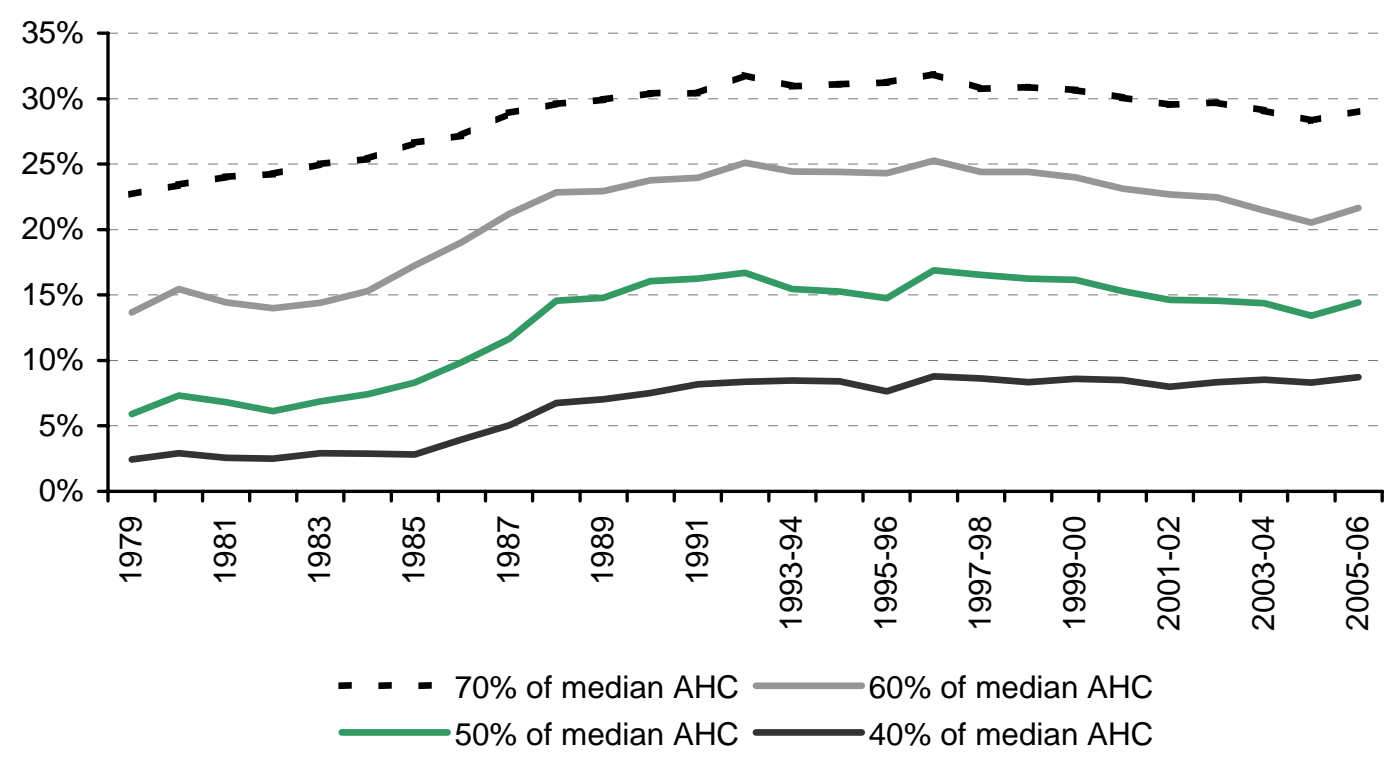

Note: Figures are presented for GB up until 2001-02 and then for the whole of the UK from 2002-03 onwards.

Source: Authors' calculations based on Family Expenditure Survey and Family Resources Survey, various years.

Figure 10b. Relative poverty: percentage of individuals in households with incomes below various fractions of median income $(\mathrm{BHC})$

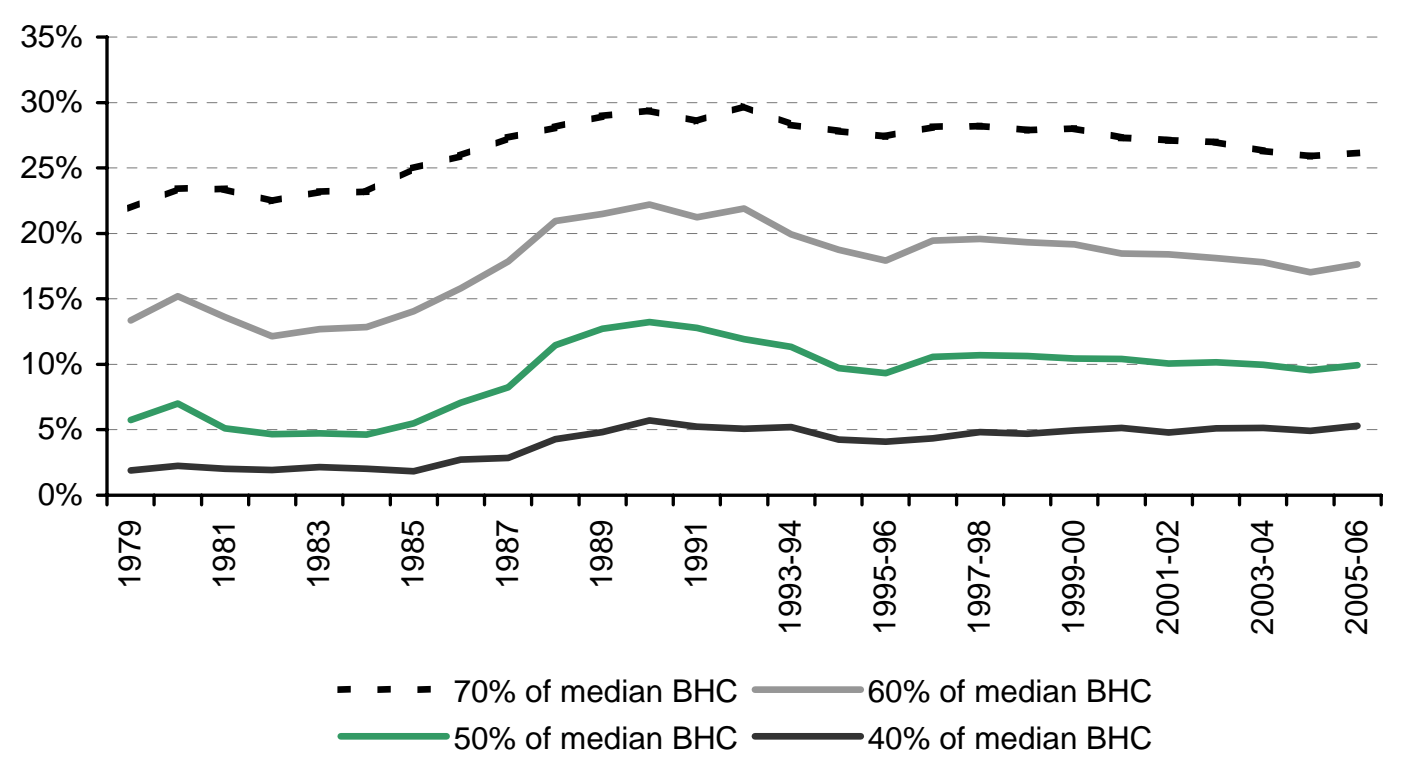

Note: Figures are presented for GB up until 2001-02 and then for the whole of the UK from 2002-03 onwards.

Source: Authors' calculations based on Family Expenditure Survey and Family Resources Survey, various years. 
Box 5. Trends in 'severe' poverty

Based on unpublished data provided by the Department for Work and Pensions, a recent policy paper released by the Conservative Party argued that the number of individuals in severe poverty had risen between 1994-95 and 2003-04 (severe poverty was taken to mean living in a household with less than $40 \%$ of median income). ${ }^{a}$ Figure 10 shows longer time series.

Measuring incomes $\mathrm{AHC}$, the risk of severe poverty has very slightly increased between 1994-95 and 2005-06, from $8.4 \%$ to $8.7 \%$; on the other hand, it has very slightly fallen since $1996-97$, when it was at $8.8 \%$. Measuring incomes $\mathrm{BHC}$, the rate of $5.3 \%$ in 2005-06 is higher than those in 1996-97 (4.3\%) and 1994-95 (4.2\%). These figures represent relatively small changes, but that the proportion of individuals with less than $40 \%$ of median income has risen in the past decade on most measures does stand in contrast to the declining proportion of individuals with incomes below higher fractions (i.e. $50 \%, 60 \%$ or $70 \%$ ) of median income.

Whether this can be seen as a failure of the government's strategy to help the poorest is open to question. On the one hand, it is certainly the case that the incomes of some of the poorest have failed to keep pace with those of the rest of society as a direct result of government policy. For example, for those without children and out of work, the income-based jobseeker's allowance (JSA) entitlement for a single person over 25 with no children has only been indexed with prices, and it fell from around $39 \%$ of the median AHC income in 1996-97 to 31\% of the median by 2005-06; for couples, the corresponding figures are $36 \%$ in $1996-97$ and $29 \%$ in $2005-06$.

On the other hand, it is generally accepted that, because the concept of income recorded in HBAI is a short-run, snapshot measure, amongst those people recorded as having very low incomes there will be some individuals who would not generally be considered poor but who do genuinely have few sources of income in the short run. For example, there are, at the very bottom of the income distribution, a disproportionate number of individuals who are self-employed, whose incomes tend to be particularly erratic. In addition, it has been found that the average spending of roughly the poorest $2 \%$ of individuals is higher than that amongst those considerably higher up the income distribution (this is based on analysis using a different survey from that used in HBAI). Because the fraction of individuals with incomes below $40 \%$ of the median is so low (especially measuring incomes $\mathrm{BHC}$ ), it can be argued that a more reliable picture of who is genuinely poor, and of changes in the numbers of those who are genuinely poor, might be obtained from examining households at the bottom of the distribution of spending rather than income. ${ }^{b}$

a Social Justice Policy Group, The State of the Nation Report: Economic Dependency,

London, December 2006

(http://povertydebate.typepad.com/home/files/volume 1 worklessness.pdf).

${ }^{\mathrm{b}} \mathrm{M}$. Brewer, A. Goodman and A. Leicester, Household Spending in Britain: What Can It Teach Us About Poverty?, Policy Press, Bristol, 2006. 
2005-06, poverty rose by 1.1 percentage points (AHC) and 0.6 percentage points (BHC). Both of these increases are statistically significant: in other words, it is highly likely that this finding accurately reflects a genuine rise in relative poverty rather than the fact that this year's survey is particularly unrepresentative of the population as a whole. This rise in relative poverty has reversed the decline in the previous year.

When we look at trends using other poverty lines $(40 \%, 50 \%$ and $70 \%$ of the median income), we see that poverty rates also increased during the 1980s using these poverty lines. Poverty has also fallen since the mid-1990s using the $50 \%$ and $70 \%$ thresholds. However, when we consider the $40 \%$ poverty line, we see that this measure of poverty has not fallen since the mid-1990s measuring incomes AHC. It has risen by 1 percentage point between 1996-97 and 2005-06 measuring incomes BHC, and this rise is statistically significantly different from zero.

\subsection{Relative poverty amongst different groups}

This section focuses on subgroups of the population, examining poverty amongst the government's favoured target groups of children and pensioners, and amongst working-age adults without dependent children.

Tables 5 and 6 contain more detailed information on relative poverty, using a $60 \%$ poverty line, since 1996-97 for the population as a whole (the last pair of columns) and for various subgroups (the other columns). They show that relative poverty rose between 2004-05 and 2005-06 for children and for working-age adults, but pensioners saw a fall in relative poverty (all true measuring incomes $\mathrm{AHC}$ or $\mathrm{BHC}$ ).

Using rounded numbers, the (net) rise in overall poverty of 600,000 measuring incomes AHC comprises 400,000 working-age adults without children, ${ }^{27}$ 200,000 working-age adults with children and 200,000 children, but 100,000 fewer pensioners. Measuring incomes BHC, the (net) rise in overall poverty of 400,000 comprises 100,000 working-age adults without children, 200,000 working-age adults with children and 100,000 children, but 100,000 fewer pensioners.

How do the changes in relative poverty since 2004-05 change our impression of the current government's record in reducing poverty?

\footnotetext{
${ }^{27}$ We use the shorthand 'working-age adults without children' or 'working-age non-parents' to refer to 'working-age adults without dependent children'.
} 
Table 5. Relative poverty: percentage and number of individuals in households with incomes below 60\% of median AHC income

\begin{tabular}{|c|c|c|c|c|c|c|c|c|c|c|}
\hline & \multicolumn{2}{|c|}{ Children } & \multicolumn{2}{|c|}{ Pensioners } & \multicolumn{2}{|c|}{$\begin{array}{l}\text { Working-age } \\
\text { parents }\end{array}$} & \multicolumn{2}{|c|}{$\begin{array}{l}\text { Working-age } \\
\text { non-parents }\end{array}$} & \multicolumn{2}{|c|}{ All } \\
\hline & $\%$ & Million & $\%$ & Million & $\%$ & Million & $\%$ & Million & $\%$ & Million \\
\hline 1996-97 (GB) & 34.1 & 4.3 & 29.1 & 2.9 & 26.6 & 3.3 & 17.2 & 3.5 & 25.3 & 14.0 \\
\hline 1997-98 (GB) & 33.2 & 4.2 & 29.1 & 2.9 & 25.9 & 3.2 & 15.9 & 3.3 & 24.4 & 13.6 \\
\hline 1998-99 (GB) & 33.9 & 4.3 & 28.6 & 2.9 & 26.3 & 3.2 & 15.5 & 3.2 & 24.4 & 13.6 \\
\hline 1999-00 (GB) & 32.7 & 4.2 & 27.6 & 2.8 & 25.5 & 3.1 & 16.1 & 3.4 & 24.0 & 13.4 \\
\hline 2000-01 (GB) & 31.1 & 3.9 & 25.9 & 2.6 & 24.7 & 3.0 & 16.2 & 3.4 & 23.1 & 13.0 \\
\hline 2001-02 (GB) & 30.8 & 3.9 & 25.6 & 2.6 & 24.5 & 3.0 & 15.6 & 3.4 & 22.7 & 12.8 \\
\hline $2002-03$ (UK) & 29.8 & 3.9 & 24.2 & 2.5 & 24.1 & 3.0 & 16.5 & 3.7 & 22.4 & 13.1 \\
\hline 2003-04 (UK) & 28.7 & 3.7 & 20.6 & 2.2 & 23.5 & 2.9 & 16.6 & 3.7 & 21.5 & 12.6 \\
\hline 2004-05 (UK) & 28.4 & 3.6 & 17.6 & 1.9 & 23.0 & 2.9 & 16.1 & 3.6 & 20.5 & 12.1 \\
\hline 2005-06 (UK) & 29.8 & 3.8 & 17.0 & 1.8 & 24.8 & 3.1 & 17.5 & 4.0 & 21.6 & 12.7 \\
\hline \multicolumn{11}{|l|}{ Changes } \\
\hline $\begin{array}{l}\text { Total: } 1996-97 \\
\text { to } 2005-06\end{array}$ & -4.3 & & -12.1 & & -1.8 & & $(0.3)$ & & -3.6 & \\
\hline $\begin{array}{l}\text { Labour I: } 1996-97 \\
\text { to } 2000-01\end{array}$ & -3.0 & & -3.2 & & -1.9 & & -1.0 & & -2.1 & \\
\hline $\begin{array}{l}\text { Labour II: 2000-01 } \\
\text { to 2004-05 }\end{array}$ & -2.8 & & -8.3 & & -1.6 & & $(-0.1)$ & & -2.6 & \\
\hline $\begin{array}{l}\text { Latest year: } 2004- \\
05 \text { to } 2005-06\end{array}$ & (1.4) & $(0.2)$ & $(-0.6)$ & $(-0.1)$ & 1.8 & 0.2 & 1.4 & 0.3 & 1.1 & 0.7 \\
\hline
\end{tabular}

Notes: Reported changes may not equal the differences between the corresponding numbers due to rounding. Changes in parentheses are not significantly different from zero at the $5 \%$ level. Changes in the number of individuals in poverty are only shown where these can be calculated consistently at the UK level. All figures are presented using the modified OECD equivalence scale.

Source: Authors' calculations based on Family Resources Survey, various years.

- Across the population, the rise in poverty in 2005-06 makes little difference to the overall impression of the government's record. During Labour's first term, overall poverty fell by 2.1 percentage points (AHC) and by 1.0 percentage points (BHC); it then fell slightly faster during the second term, falling by a further 2.6 percentage points (AHC) and 1.4 percentage points (BHC). All of these declines are statistically significant, and clearly much larger than the rise between 2004-05 and 2005-06.

- There were also substantial falls in relative poverty amongst children and pensioners between 1996-97 and 2004-05, measuring incomes both AHC and BHC. For children the fall was faster during the first term, while for pensioners it was faster during the second term. As with the whole 
population, the record on child and pensioner poverty is still one of a substantial decline in relative poverty since 1996-97.

- However, there has not been a consistent fall in relative poverty amongst working-age non-parents, a group not favoured by current government policy. Although this group has a lower-than-average risk of falling into poverty, this risk changed little over the first two terms of office of the current government: in 2004-05, the risk was little different from that in 1997-98, and after the rise in 2005-06, the risk of relative poverty for working-age non-parents is now a little higher than it was in 1996-97. (This analysis of relative poverty amongst working-age non-parents is based on incomes measured AHC; measured BHC, the trends are less favourable: the 1996-97 level of relative poverty has been exceeded in every year since 1999-00 (see Table 6).)

Table 6. Relative poverty: percentage and number of individuals in households with incomes below $60 \%$ of median BHC income

\begin{tabular}{|c|c|c|c|c|c|c|c|c|c|c|}
\hline & \multicolumn{2}{|c|}{ Children } & \multicolumn{2}{|c|}{ Pensioners } & \multicolumn{2}{|c|}{$\begin{array}{l}\text { Working-age } \\
\text { parents }\end{array}$} & \multicolumn{2}{|c|}{$\begin{array}{l}\text { Working-age } \\
\text { non-parents }\end{array}$} & \multicolumn{2}{|c|}{ All } \\
\hline & $\%$ & Million & $\%$ & Million & $\%$ & Million & $\%$ & Million & $\%$ & Million \\
\hline 1996-97 (GB) & 26.7 & 3.4 & 24.6 & 2.4 & 20.2 & 2.5 & 12.0 & 2.5 & 19.4 & 10.8 \\
\hline 1997-98 (GB) & 26.9 & 3.4 & 25.3 & 2.5 & 20.4 & 2.5 & 11.9 & 2.5 & 19.6 & 10.9 \\
\hline 1998-99 (GB) & 26.0 & 3.3 & 26.8 & 2.7 & 19.6 & 2.4 & 11.5 & 2.4 & 19.3 & 10.8 \\
\hline 1999-00 (GB) & 25.6 & 3.3 & 25.1 & 2.5 & 19.8 & 2.4 & 12.1 & 2.6 & 19.2 & 10.7 \\
\hline 2000-01 (GB) & 23.3 & 3.0 & 24.8 & 2.5 & 18.1 & 2.2 & 12.8 & 2.7 & 18.4 & 10.4 \\
\hline 2001-02 (GB) & 23.1 & 2.9 & 25.1 & 2.5 & 18.3 & 2.2 & 12.5 & 2.7 & 18.4 & 10.4 \\
\hline 2002-03 (UK) & 22.6 & 2.9 & 24.4 & 2.5 & 18.0 & 2.2 & 12.7 & 2.8 & 18.1 & 10.6 \\
\hline 2003-04 (UK) & 22.1 & 2.9 & 22.9 & 2.4 & 17.9 & 2.2 & 12.8 & 2.9 & 17.8 & 10.4 \\
\hline 2004-05 (UK) & 21.3 & 2.7 & 21.3 & 2.3 & 16.9 & 2.1 & 12.6 & 2.9 & 17.0 & 10.0 \\
\hline 2005-06 (UK) & 22.1 & 2.8 & 20.8 & 2.2 & 18.2 & 2.3 & 13.3 & 3.0 & 17.6 & 10.4 \\
\hline \multicolumn{11}{|l|}{ Changes } \\
\hline $\begin{array}{l}\text { Total: } 1996-97 \\
\text { to } 2005-06\end{array}$ & -4.6 & & -3.8 & & -1.9 & & 1.2 & & -1.8 & \\
\hline $\begin{array}{l}\text { Labour I: } 1996-97 \\
\text { to } 2000-01\end{array}$ & -3.4 & & $(0.1)$ & & -2.0 & & $(0.7)$ & & -1.0 & \\
\hline $\begin{array}{l}\text { Labour II: } 2000-01 \\
\text { to } 2004-05\end{array}$ & -2.0 & & -3.5 & & -1.2 & & $(-0.2)$ & & -1.4 & \\
\hline $\begin{array}{l}\text { Latest year: } 2004- \\
05 \text { to } 2005-06\end{array}$ & $(0.8)$ & $(0.1)$ & $(-0.5)$ & $(-0.1)$ & 1.3 & 0.2 & $(0.6)$ & $(0.1)$ & 0.6 & 0.4 \\
\hline
\end{tabular}

Notes: Reported changes may not equal the differences between the corresponding numbers due to rounding. Changes in parentheses are not significantly different from zero at the $5 \%$ level. Changes in the number of individuals in poverty are only shown where these can be calculated consistently at the UK level. All figures are presented using the modified OECD equivalence scale.

Source: Authors' calculations based on Family Resources Survey, various years. 
Table 7. Growth in entitlements to state support for certain family types

\begin{tabular}{c|ccccccc|c}
\hline & $\begin{array}{c}\text { Couple, } \\
\text { 3 children, } \\
\text { not } \\
\text { working }\end{array}$ & $\begin{array}{c}\text { Lone } \\
\text { parent, } \\
\text { 1 child, } \\
\text { not } \\
\text { working }\end{array}$ & $\begin{array}{c}\text { Lone } \\
\text { parent, } \\
\text { 1 child, } \\
\text { part- } \\
\text { time } \\
\text { work }\end{array}$ & $\begin{array}{c}\text { Single } \\
\text { person, } \\
\text { unemp'd, } \\
\text { i.e. JSA }\end{array}$ & $\begin{array}{c}\text { Single } \\
\text { person, } \\
\text { IB }\end{array}$ & $\begin{array}{c}\text { Single } \\
\text { pensioner }\end{array}$ & $\begin{array}{c}\text { Couple } \\
\text { pensioner }\end{array}$ & $\begin{array}{c}\text { Poverty } \\
\text { line } \\
\text { (AHC) }\end{array}$ \\
\hline $1997-98$ & -0.8 & 0.1 & 0.0 & 0.6 & 0.1 & 0.6 & 0.6 & \\
$1998-99$ & -0.9 & -5.7 & -7.3 & 0.4 & 1.6 & 0.4 & 0.4 & 1.8 \\
$1999-00$ & $\mathbf{6 . 8}$ & $\mathbf{7 . 1}$ & $\mathbf{7 . 7}$ & 0.6 & 1.7 & $\mathbf{4 . 9}$ & $\mathbf{5 . 1}$ & 3.1 \\
$2000-01$ & $\mathbf{1 1 . 2}$ & $\mathbf{7 . 0}$ & $\mathbf{1 6 . 2}$ & -0.1 & -0.6 & 2.9 & 2.8 & 3.1 \\
$2001-02$ & $\mathbf{7 . 0}$ & 4.6 & $\mathbf{5 . 4}$ & 0.0 & 1.6 & $\mathbf{1 5 . 5}$ & $\mathbf{1 3 . 4}$ & 4.9 \\
$2002-03$ & $\mathbf{2 . 1}$ & $\mathbf{1 . 8}$ & $\mathbf{2 . 7}$ & 0.3 & 0.3 & $\mathbf{5 . 0}$ & $\mathbf{5 . 1}$ & 1.8 \\
$2003-04$ & $\mathbf{6 . 7}$ & $\mathbf{4 . 9}$ & $\mathbf{5 . 8}$ & -0.3 & $\mathbf{0 . 1}$ & $\mathbf{2 . 7}$ & $\mathbf{2 . 4}$ & 0.0 \\
$2004-05$ & $\mathbf{4 . 3}$ & $\mathbf{3 . 3}$ & $\mathbf{3 . 7}$ & 0.6 & $\mathbf{1 . 5}$ & $\mathbf{1 . 7}$ & $\mathbf{2 . 0}$ & 1.0 \\
$2005-06$ & 0.5 & 0.3 & $\mathbf{1 . 3}$ & -0.7 & $\mathbf{1 . 3}$ & $\mathbf{2 . 0}$ & $\mathbf{2 . 0}$ & 0.9 \\
\hline $2006-07$ & 0.1 & -0.3 & 0.0 & -0.8 & -0.3 & 1.2 & 1.2 & n/a \\
$2007-08$ & 1.3 & 1.0 & 1.4 & 0.6 & 1.4 & 2.1 & 1.7 & n/a \\
\hline
\end{tabular}

Notes: Table shows annual changes in maximum entitlements to benefits for various family types with no private income (except the working lone parent, who is assumed to earn an amount that is below the personal income tax allowance and the primary threshold for National Insurance contributions) ignoring housing benefit and council tax benefit. Nominal values are then deflated by the AHC deflator. Values in bold are greater than the growth in the poverty line. For further details, contact authors.

Source: Authors' calculations.

The majority of net income of individuals in the second and third deciles (i.e. roughly those just below and just above the poverty line) comes from state benefits and tax credits, so clearly what happens to changes to the generosity of benefits is a key determinant of what happens to relative poverty. Table 7 therefore shows year-on-year growth rates in entitlements to social security benefits and tax credits for some key family types represented in relative poverty, and compares these growth rates with the year-on-year changes in median income, and therefore the poverty line (measuring incomes AHC). ${ }^{28}$ Numbers in bold in the table mark the instances where entitlements to benefits grew by more than the poverty line, a factor that, considered in isolation, would suggest a declining relative poverty rate for that family type.

Table 7 shows the following:

${ }^{28}$ Comparisons are made with the poverty line measuring incomes AHC because families such as these would (mostly) be entitled to housing benefit covering all of their rent. 
- For most of the family types shown, the growth in maximum entitlements to benefits and tax credits in 2005-06 was relatively small compared with previous years.

- For some families with children, the growth in maximum entitlements to benefits and tax credits in 2005-06 was below the growth in the poverty line (measuring incomes AHC) for the first time since 1998-99.

- Since 2000-01, the growth in maximum entitlements to benefits for pensioner families with no private income has exceeded the growth in the poverty line (measuring incomes AHC). Since 2003-04, this has been because maximum entitlements to benefits rise each year in line with average earnings, growth in which has tended to be above the growth in median income (measuring incomes AHC).

- The level of jobseeker's allowance (JSA) for a single unemployed person has risen more slowly than the poverty line in every year since 1996-97.

- In recent years, the value of incapacity benefit (IB) has grown by more than the poverty line. This is because IB (unlike JSA) is indexed each year in line with changes in the RPI, which have been considerably higher than changes in the ROSSI index in recent years. ${ }^{29}$

Although many other things affect the level of incomes received by those around the poverty line, it is striking that the rise in child poverty came during a year with particularly small real rises in entitlements to benefits and tax credits. $^{30}$

The last two rows of Table 7 show the projected increase in entitlement for the various family types in 2006-07 and 2007-08. Since the annual average inflation rate (AHC) is not yet known, we have had to assume it is equal to the September 2006 value for 2006-07 (which is known) and to the Treasury's

\footnotetext{
${ }^{29}$ The ROSSI index is a measure of inflation that excludes housing costs, rent and council taxes, and it is used as the default index by which many means-tested benefits are annually uprated. These benefits include JSA and income support.

${ }^{30}$ The per-child element of the child tax credit has been increased at least in line with average earnings since 2004-05. However, a non-working family with children also receives income from child benefit (increased in line with RPI), income support (increased in line with ROSSI) and the family element of the child tax credit (frozen in nominal terms), so the total value of state support will increase by considerably less than average earnings, as can be seen by comparing the growth in entitlements for non-working families with those for pensioners. Working families with children do not receive income support, but they do receive working tax credit, which is increased in line with RPI.
} 
projected value for 2007-08. This is far from ideal, but even if we make different assumptions, future growth in entitlement in future years seems set to be relatively low.

The changes in poverty amongst children, pensioners, and working-age adults without dependent children are now explored in more detail.

\section{Child poverty}

The number of children living in poverty in the UK in 2005-06 was 3.8 million (AHC) and 2.8 million (BHC), up 200,000 and 100,000 from 2004-05 (or rises of 1.4 percentage points (AHC) and 0.8 percentage points (BHC)). Neither of these changes is statistically different from zero at the $5 \%$ level, but both are unusual, coming after six successive years of falls in child poverty.

Table 8. Decomposition of the rise in relative child poverty (BHC), 2004-05 to 2005-06

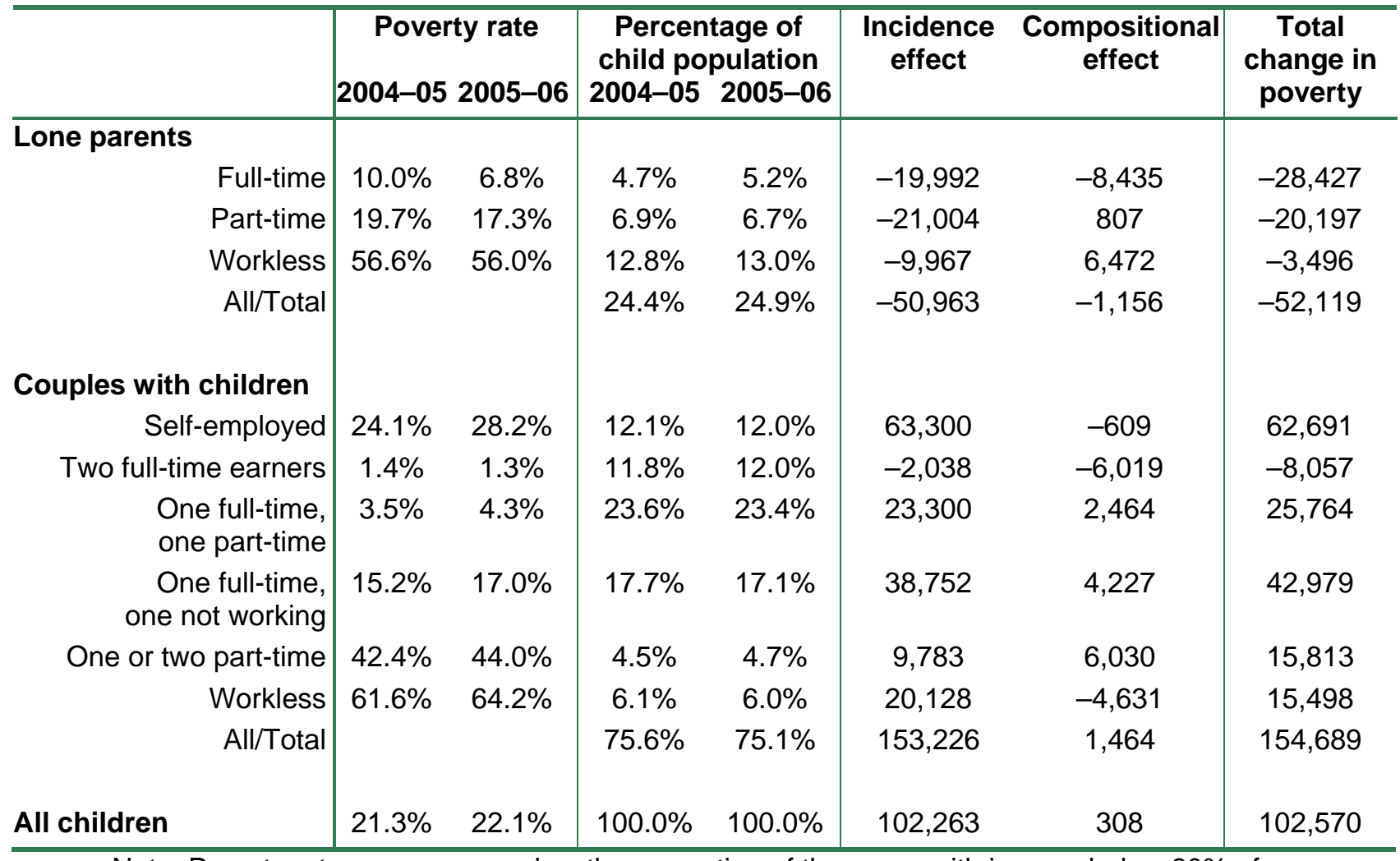

Note: Poverty rates are measured as the proportion of the group with income below $60 \%$ of the population-wide BHC median income.

Source: Authors' calculations based on Family Resources Survey, 2004-05 and 2005-06. 
A decomposition of the change in child poverty from 2004-05 can help tell us why child poverty rose, and Table 8 gives such a breakdown. ${ }^{31}$ The principle behind the table is to divide all children into nine family types (according to the number of adults in the family and their working patterns), and then divide all changes in poverty into incidence effects - which represent changes in the risk of poverty for particular family types - and compositional effects - which reflect changes in the distribution of children between these nine family types. It should be pointed out, though, that given that the overall rise in child poverty was not statistically different from zero, it is highly likely that the same is true for the estimated incidence and compositional effects in Table 8; they do, however, explain the mechanics of why child poverty has risen.

The bottom row of Table 8 shows that the overwhelming majority of the rise in child poverty is due to incidence effects: poverty rose chiefly because the risk of poverty rose for particular family types. ${ }^{32}$ Furthermore, there is a clear difference between the changes in child poverty in lone-parent and couple families:

- The pattern of incidence effects across family types shows us that the rise in child poverty in 2005-06 is chiefly due to a rise in the risk of poverty for children in couple families: the risk of relative poverty fell for children in the three types of lone-parent families but rose for children in all two-parent family types except those with two full-time earners.

- In addition, the sum of the compositional effects for children in lone-parent families is negative (acts to reduce child poverty) despite more children living in lone-parent families in 2005-06 than in 2004-05. On average, children in lone-parent families have a higher risk of poverty than children in couple families, but the continuing rise in the proportion of lone parents who work - a factor that acts to lower the risk of poverty - more than outweighs the former factor.

\footnotetext{
${ }^{31}$ For more details, see appendix D of M. Brewer, A. Goodman, J. Shaw and L. Sibieta, Poverty and Inequality in Britain: 2006, Commentary no. 101, Institute for Fiscal Studies, London, 2006 (http://www.ifs.org.uk/comms/comm101.pdf). The authors acknowledge that they were motivated to present these decompositions by the analysis in $\mathrm{H}$. Sutherland, $\mathrm{T}$. Sefton and D. Piachaud, Poverty in Britain, Joseph Rowntree Foundation, York, 2003.

${ }^{32}$ Note that the relative importance of incidence and compositional effects is sensitive to the number and definition of family types used in the decomposition.
} 
Manipulation of the numbers in Table 8 reveals that the fraction of children in poverty who live in couple families rose from $57.4 \%$ in $2004-05$ to $60.3 \%$ in 2005-06, and the fraction in families with someone in work rose from $48.4 \%$ to $49.9 \% .^{33}$ Both changes may well increase the desire to introduce income tax or tax credit reforms that direct more support to couples with children or to working (rather than non-working) parents. ${ }^{34}$

The government had a target for child poverty in Britain in 2004-05 to be onequarter lower than its 1998-99 level. We discovered last year that this target had been missed: using the measure used to assess this target, child poverty needed to have fallen by a further 100,000 to meet the target measuring incomes BHC, and by 300,000 measuring incomes AHC. ${ }^{35}$ The target does not apply to 2005-06, and the government has since chosen a different way to measure child poverty for its future targets. However, the rise in child poverty between 2004-05 and 2005-06 means that the government is still short of its 2004-05 target by 200,000 measuring incomes BHC or by 400,000 measuring incomes AHC, achieving reductions of only $18.0 \%$ and $14.0 \%$ respectively between 1998-99 and 2005-06: see Figure 11 and Table 9.

The government has another target for child poverty in the UK in 2010-11 to be one-half its 1998-99 level. Progress will be assessed using three definitions of poverty - a relative poverty measure, an absolute poverty measure and a material deprivation measure - all of which are different from the ones used for the target for child poverty in 2004-05. ${ }^{36}$

\footnotetext{
${ }^{33}$ Note, though, that the risk of poverty is still higher for children in lone-parent families than for those in couple families.

${ }^{34}$ For a discussion of some options, see M. Brewer, 'Supporting couples with children through the tax system', in R. Chote, C. Emmerson, A. Leicester and D. Miles (eds), The IFS Green Budget 2007, IFS, London, 2007 (http://www.ifs.org.uk/budgets/gb2007/07chap12.pdf).

${ }^{35}$ See M. Brewer, A. Goodman, J. Shaw and L. Sibieta, Poverty and Inequality in Britain: 2006, Commentary no. 101, IFS, London, 2006 (http://www.ifs.org.uk/comms/comm101.pdf). Note that this was measured using the McClements equivalence scale, rather than the modified OECD equivalence scale, so that the numbers presented above are different from those that were used to assess progress towards this target.

${ }^{36}$ See Department for Work and Pensions, Measuring Child Poverty, London, 2003. At present, the DWP has a PSA target to reduce child poverty defined in terms of the relative poverty measure, and is expected to have one based on the material deprivation measure as part of the 2007 Comprehensive Spending Review.
} 
Figure 11. The government's first child poverty target: actual and required path of child poverty, 1998-99 to 2005-06

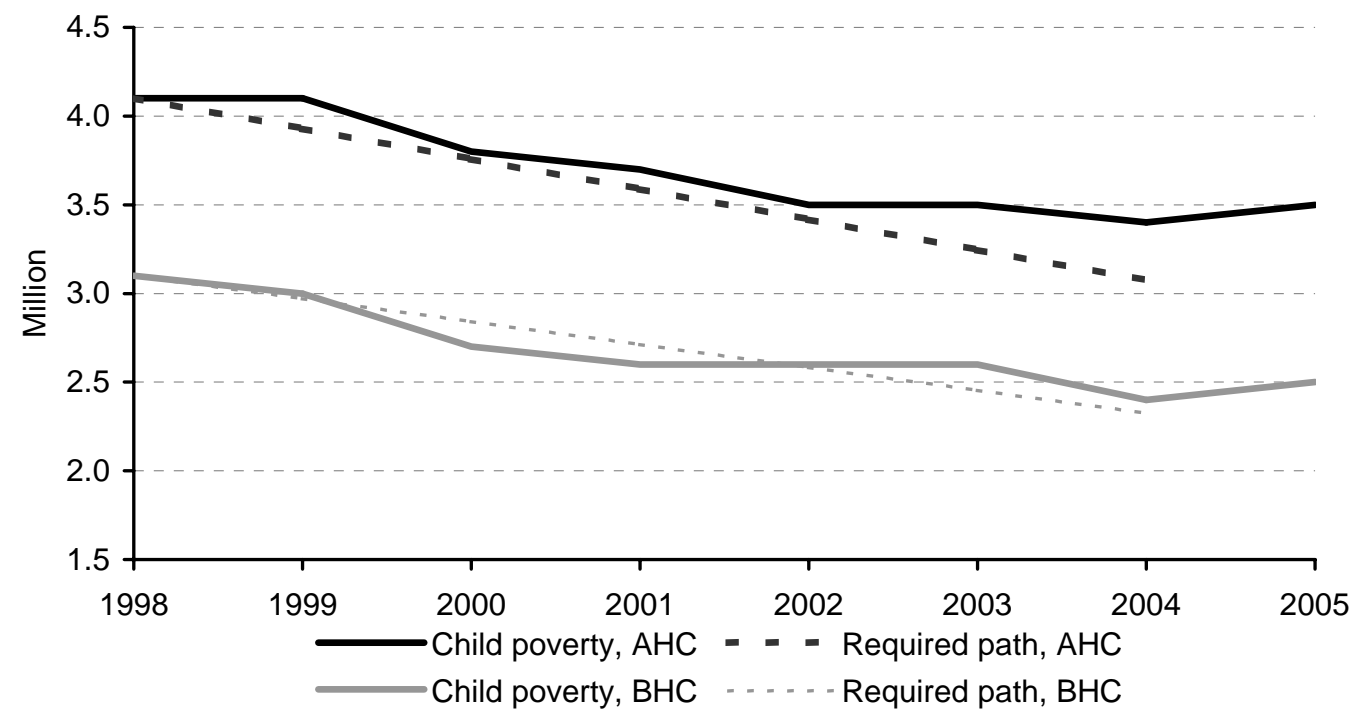

Notes: Years are financial years (e.g. 1998 refers to financial year 1998-99). Child poverty is defined as living in households in Great Britain with less than $60 \%$ of median household income using the McClements equivalence scale.

Source: Authors' calculations based on the Family Resources Survey, various years.

Table 9. Progress towards halving child poverty by 2010-11

\begin{tabular}{|c|c|c|c|c|c|c|c|c|}
\hline & \multicolumn{2}{|c|}{$\begin{array}{c}\text { Relative } \\
\text { poverty, UK, } \\
\text { modified OECD } \\
\text { (BHC) }\end{array}$} & \multicolumn{2}{|c|}{$\begin{array}{c}\text { Absolute } \\
\text { poverty, UK, } \\
\text { nodified OECD } \\
\text { (BHC) }\end{array}$} & \multicolumn{2}{|c|}{$\begin{array}{c}\text { Relative } \\
\text { poverty, GB, } \\
\text { McClements } \\
\text { (BHC) }\end{array}$} & \multicolumn{2}{|c|}{$\begin{array}{c}\text { Relative } \\
\text { poverty, GB, } \\
\text { McClements } \\
\text { (AHC) }\end{array}$} \\
\hline & $\%$ & Million & $\%$ & Million & $\%$ & Million & $\%$ & Million \\
\hline 1998-99 & 26.1 & 3.4 & 26.1 & 3.4 & 24.5 & 3.1 & 32.5 & 4.1 \\
\hline 1999-00 & 25.7 & 3.4 & & & 23.4 & 3.0 & 31.9 & 4.1 \\
\hline 2000-01 & 23.4 & 3.1 & & & 21.0 & 2.7 & 30.3 & 3.8 \\
\hline 2001-02 & 23.2 & 3.0 & & & 20.7 & 2.6 & 29.6 & 3.7 \\
\hline $2002-03$ & 22.6 & 2.9 & 14.1 & 1.8 & 20.6 & 2.6 & 28.3 & 3.5 \\
\hline 2003-04 & 22.1 & 2.9 & 13.7 & 1.8 & 20.5 & 2.6 & 27.9 & 3.5 \\
\hline 2004-05 & 21.3 & 2.7 & 12.9 & 1.7 & 19.6 & 2.4 & 27.3 & 3.4 \\
\hline 2005-06 & 22.1 & 2.8 & 12.7 & 1.6 & 20.5 & 2.5 & 28.6 & 3.5 \\
\hline $\begin{array}{l}\text { Memo: original target } \\
\text { for } 2004-05\end{array}$ & & & & & & 2.3 & & 3.1 \\
\hline Target for 2010-11 & & 1.7 & & & & & & \\
\hline
\end{tabular}

Notes: Reported changes may not equal the differences between the corresponding numbers due to rounding. The left-hand panel uses data from UK and incomes equivalised using the modified OECD equivalence scale. The right-hand panel uses data from GB and incomes equivalised using the McClements equivalence scale. For the purposes of the child poverty target in 2010-11, the DWP has had to estimate the level of relative child poverty in the UK in 1998-99 (Northern Ireland was first included in the official HBAI series in 2002-03).

Sources: Authors' calculations based on Family Resources Survey, various years. 
Figure 12. Actual, required and projected path of child poverty, 1998-99 to 2010-11

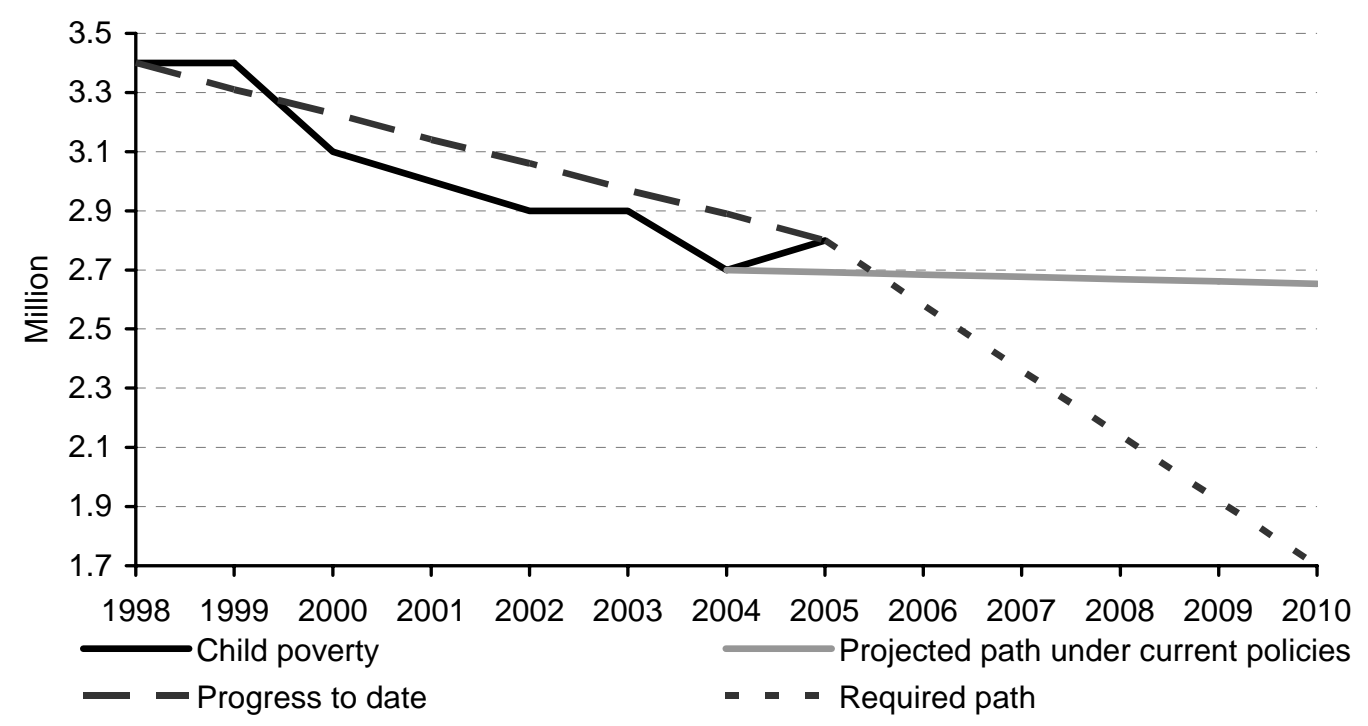

Notes: Years are financial years (e.g. 1998 refers to financial year 1998-99). Child poverty is defined as living in households in the UK with less than $60 \%$ of median household income using the modified OECD equivalence scale.

Source: Authors' calculations based on the Family Resources Survey, various years. 'Projected path under current policies' from M. Brewer, J. Browne and H. Sutherland, MicroSimulating Child Poverty in 2010 and 2020, Joseph Rowntree Foundation, York, July 2006 (http://www.jrf.org.uk/bookshop/eBooks/9781859355091.pdf).

We have previously argued that the most binding of the government's three measures will be the pure relative poverty target, which is for child poverty in the UK in 2010-11 to be one-half lower than its level in 1998-99, using a poverty line of $60 \%$ of median BHC income and the modified OECD equivalence scale. ${ }^{37}$ Under this definition of poverty (which is now the one used throughout HBAI), the number of children in poverty rose between 200405 and 2005-06 to reach 2.8 million; this means that child poverty has fallen by 600,000 (or $17.2 \%$ ) in the seven years since 1998-99, and needs to fall by a further 1.1 million in the remaining five years between now and 2010-11 to meet this element of the target: see Figure 12 and Table 9. Thus, child poverty needs to fall by an average of over 200,000 for the next five years, having fallen by an average of less than 100,000 a year for the past seven years.

Previous work estimated that, if the government stuck to the increases for benefits, tax allowances and tax credits that are assumed in its public finance

\footnotetext{
${ }^{37}$ M. Brewer, A. Goodman, J. Shaw and A. Shephard, Poverty and Inequality in Britain: 2005, IFS Commentary no. 99, 2005 (http://www.ifs.org.uk/publications.php?publication id=3328).
} 
forecasts, then the rate of child poverty would rise very slightly between 200405 and 2010-11 (but the number of children in poverty would fall very slightly, as the number of dependent children is forecast to fall). That work also estimated that extra spending on tax credits and child benefit of around $£ 4.5$ billion a year by 2010-11 would give the government a 50:50 chance of meeting its target. ${ }^{38}$

The levels of key benefits and tax credits affecting families with children in 2005-06 were known at the time that the aforementioned work forecasting child poverty to 2010-11 took place, and so it is informative to compare the level of child poverty in 2005-06 with that suggested by an interpolation of the level of child poverty in 2004-05 and the forecast for 2010-11 (see 'Projected path under current policies' on Figure 12). Child poverty is now higher than forecast a year ago, but only by 100,000 , which is not a statistically significant difference.

Budget 2007 announced considerable changes to tax credits and income tax which will affect the incomes of low-income families with children (as well as the level of median income in future years). ${ }^{39}$ We agree with the assessment made by HM Treasury that the measures in Budget 2007 mean that child poverty will be 200,000 lower than if they had not been introduced. ${ }^{40}$ The assessment a year ago was that current policies would mean that the number of children in poverty in 2010-11 would be 1 million higher than the government's target; after Budget 2007, this estimate has been revised down to 800,000 . Similarly, our revised estimate taking into account the measures in Budget 2007 is that additional new spending of around $£ 4$ billion a year (on the per-child element of the child tax credit) by $2010-11$ is still needed for the government to have a 50:50 chance of meeting its target.

However, what is now clearer than a year ago is that finding an extra $£ 4$ billion a year to spend on tax credits for families with children over and above what is assumed in the government's public finance forecasts will be possible only by a very tight spending settlement in the forthcoming Comprehensive Spending

\footnotetext{
${ }^{38}$ M. Brewer, J. Browne and H. Sutherland, Micro-Simulating Child Poverty in 2010 and 2020, Joseph Rowntree Foundation, York, July 2006 (http://www.jrf.org.uk/bookshop/eBooks/9781859355091.pdf).

${ }^{39}$ HM Treasury, Budget 2007: Building Britain's Long-Term Future: Prosperity and Fairness for Families, HC 342 (2006/07 session), TSO, London, 2007 (http://www.hmtreasury.gov.uk/budget/budget 07/bud bud07 index.cfm).

${ }^{40}$ Box 5.1, Budget 2007. 
Review on areas of public services such as the NHS, defence, transport and environmental protection, or by making substantial (and as-yet unannounced) savings in other social security spending programmes. A more plausible scenario is that the government delays earmarking the resources needed for meeting its child poverty targets to future years (although the latest it can wait to announce policies is Autumn 2009, when tax credits and benefit rates for April 2010 need to be set), hoping, perhaps, for buoyant tax revenues or underspending in other areas of government. Such a policy, though, increases the risk that either the child poverty target will be missed or that new tax-raising measures will be needed in future Budgets. Furthermore, it would surely be in the interests of children currently in poverty to be lifted out of poverty sooner rather than later.

\section{Pensioner poverty}

As seen in Tables 5 and 6, in contrast to poverty amongst all individuals, pensioner poverty continued to fall in 2005-06. It fell by 0.6 percentage points from $17.6 \%$ to $17.0 \%$ (AHC) and by 0.5 percentage points from $21.3 \%$ to $20.8 \%$ (BHC). Unlike last year, neither of these changes is statistically different from zero.

Using a poverty line of $60 \%$ median income, there are now 1.8 million pensioners in poverty (AHC) and 2.2 million (BHC) in the UK. This means that when measuring incomes AHC, a pensioner chosen at random in 2005-06 is much less likely to be in poverty than an individual selected at random from the rest of the population. This gap emerged for the first time in 2003-04, and has now grown to a difference of 5.7 percentage points in 2005-06 (the respective poverty rates in $2005-06$ being $17.0 \%$ for pensioners and $22.7 \%$ for non-pensioners, the latter of which is not presented in Table 5).

Tables 5 and 6 also set out poverty rates amongst pensioners since 1996-97. ${ }^{41}$ Measuring incomes AHC, pensioner poverty has declined extremely rapidly: the 12.1 percentage point fall since $1996-97$ at $60 \%$ of median AHC income constitutes a cut in poverty of more than a third. There has also been a fall in pensioner poverty measuring incomes BHC, of 3.8 percentage points between 1996-97 and 2005-06 (a proportional fall of just under a sixth). These falls in pensioner poverty (BHC or AHC) tended to be concentrated during the current government's second term rather than its first term.

\footnotetext{
${ }^{41}$ They show the poverty rate amongst individuals above the current pension age - 65 for men and 60 for women - regardless of who else lives in their household.
} 
Figure 13a. Relative poverty: percentage of pensioners living in households with incomes below various fractions of median income (AHC)

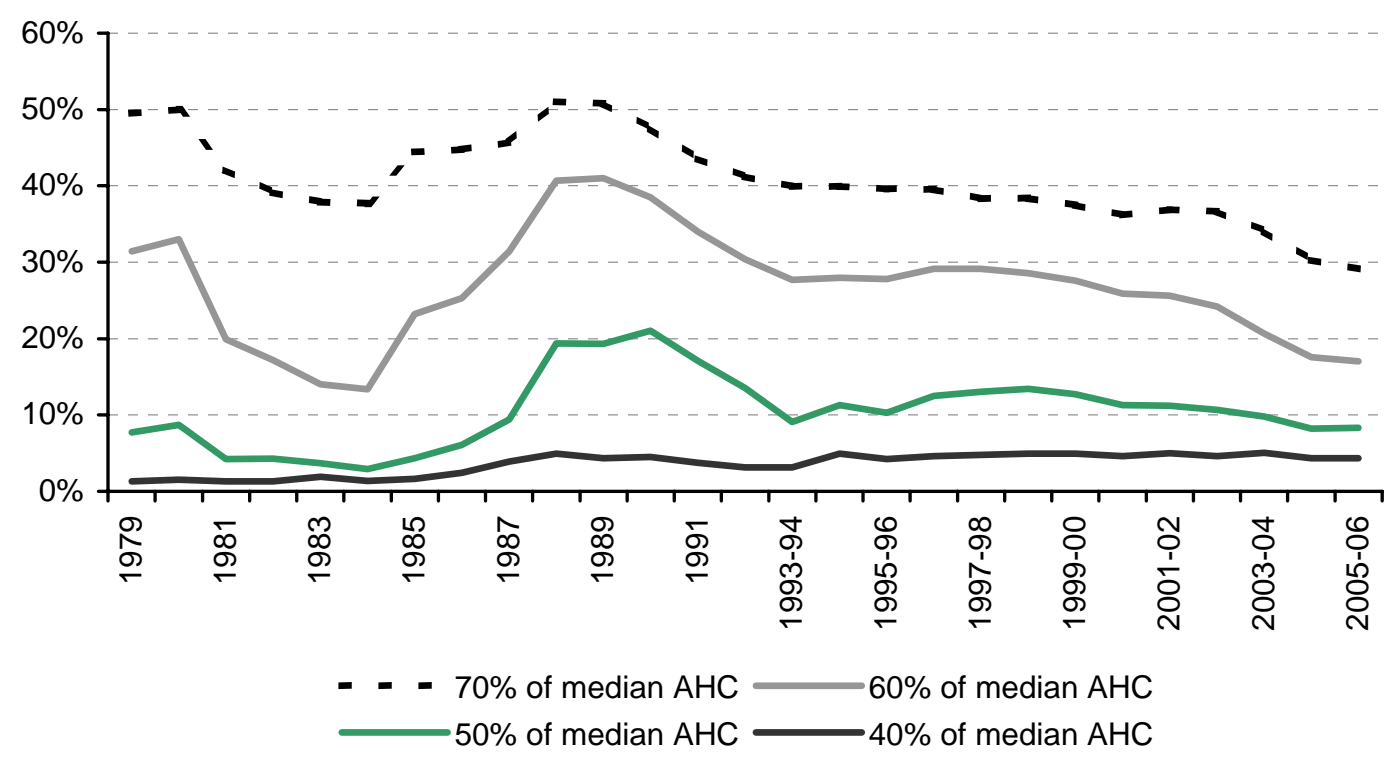

Note: Figures are presented for GB up until 2001-02 and then for the whole of the UK from 2002-03 onwards.

Source: Authors' calculations based on Family Expenditure Survey and Family Resources Survey, various years.

Figure 13b. Relative poverty: percentage of pensioners living in households with incomes below various fractions of median income $(\mathrm{BHC})$

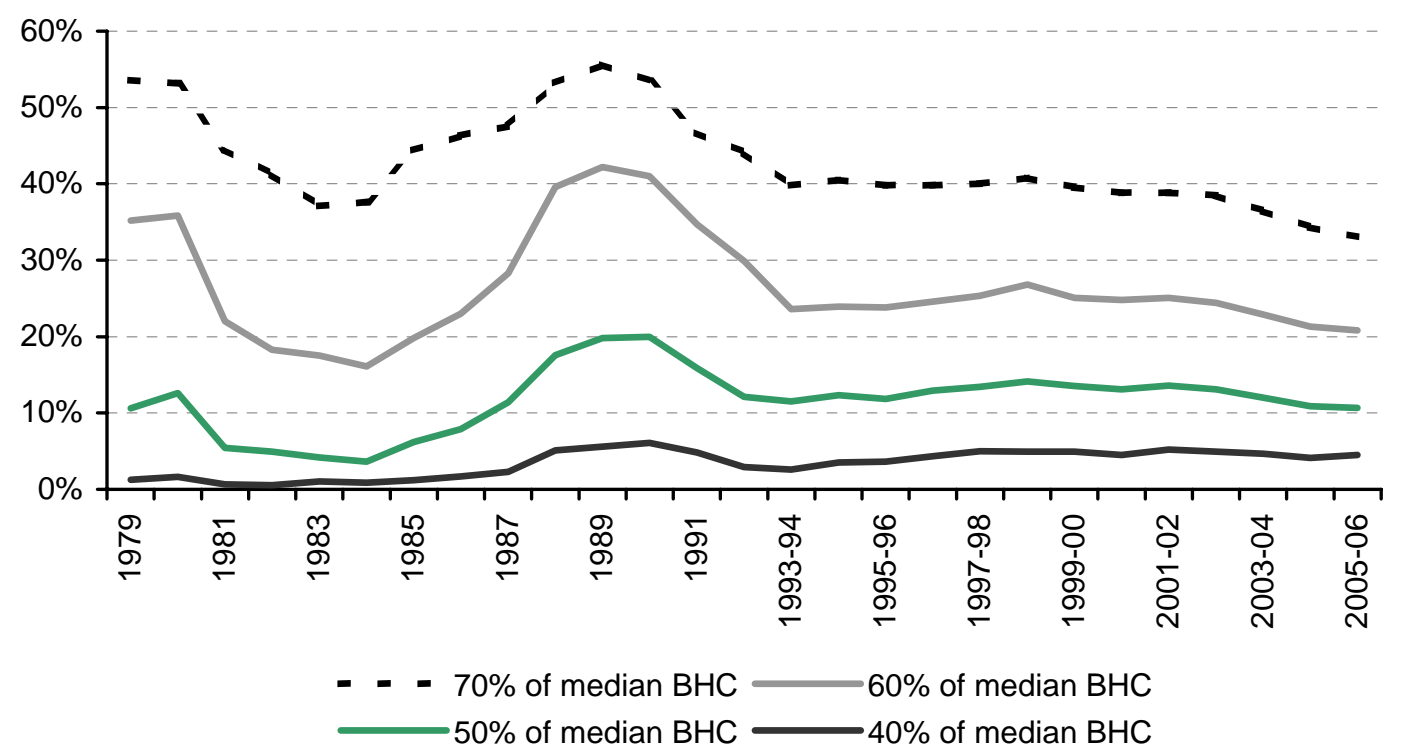

Note: Figures are presented for GB up until 2001-02 and then for the whole of the UK from 2002-03 onwards.

Source: Authors' calculations based on Family Expenditure Survey and Family Resources Survey, various years. 
Figure 13 shows how pensioner poverty has evolved over a longer time frame (since 1979). The graph shows that it has fallen using a variety of thresholds measuring incomes AHC (Figure 13a) or BHC (Figure 13b). ${ }^{42}$

\section{Poverty among working-age adults with no dependent children}

Poverty among the remainder of the population - working-age adults - has changed little since 1996-97. Because income is measured at the household level, poverty among working-age parents is likely to follow a similar path to that among children, and for this reason it is informative to consider workingage adults without children separately from working-age parents, as was done in Tables 5 and 6 (this approach is different from what is done in Opportunity for All, which only presents poverty rates for working-age individuals as a whole).

Using a poverty threshold of $60 \%$ of the median, there are now 4.0 million working-age non-parents living in poverty in the UK measuring incomes AHC (3.0 million BHC). This represents a statistically significant rise of 300,000 from 2004-05, the largest annual rise since 1990 (assessed on unrounded numbers); measuring incomes BHC, the rise was 100,000, which is not statistically different from zero and was the largest annual rise since 2000-01 (on unrounded numbers).

The rates of poverty for this group are now 17.5\% (AHC) and 13.3\% (BHC), which are both the highest recorded poverty rates amongst working-age nonparents since the start of our consistent time series in 1961. This is also true for other relative poverty thresholds. (See Figure 14.)

Table 10 decomposes the change in the rate of poverty amongst working-age non-parents since 1996-97, measuring incomes AHC, into changes in the risk of being in poverty for particular groups (the incidence effect) and the changing composition of the working-age non-parent population (the compositional effect). The groups that we have chosen to decompose the change by are very similar to those we chose to use earlier for decomposing the rise in child

\footnotetext{
${ }^{42}$ Chapter 3 of M. Brewer, A. Goodman, J. Shaw and L. Sibieta, Poverty and Inequality in Britain: 2006, Commentary no. 101, IFS, London, 2006 (http://www.ifs.org.uk/comms/comm101.pdf) showed how around one-quarter of the fall in relative poverty amongst pensioners (AHC) since 1996-97 could be attributed to compositional effects, as new (and relatively well-off) cohorts of adults reach the pension age and older (and relatively poor) cohorts die.
} 
Figure 14a. Relative poverty: percentage of working-age non-parents living in households with incomes below various fractions of median income (AHC)

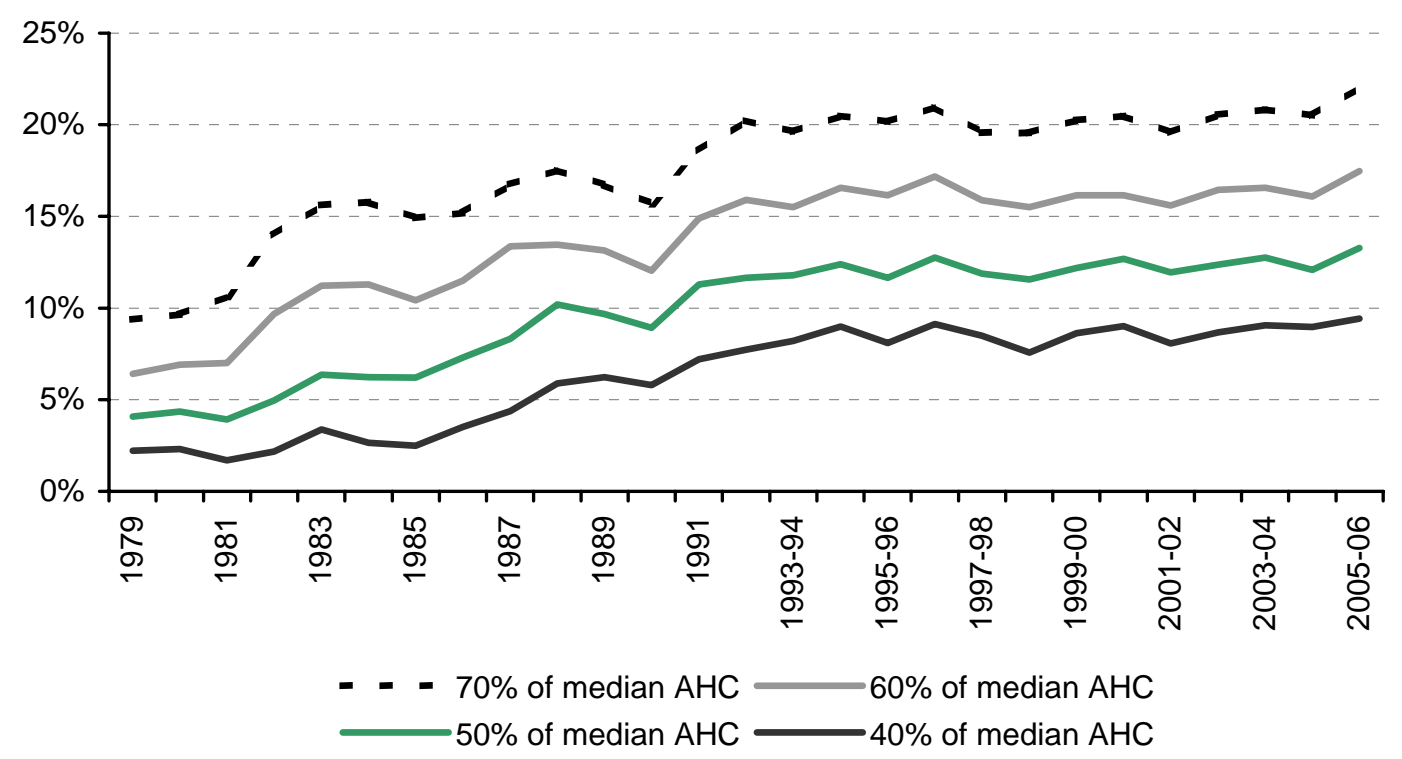

Note: Figures are presented for GB up until 2001-02 and then for the whole of the UK from 2002-03 onwards.

Source: Authors' calculations based on Family Expenditure Survey and Family Resources Survey, various years.

Figure 14b. Relative poverty: percentage of working-age non-parents living in households with incomes below various fractions of median income (BHC)

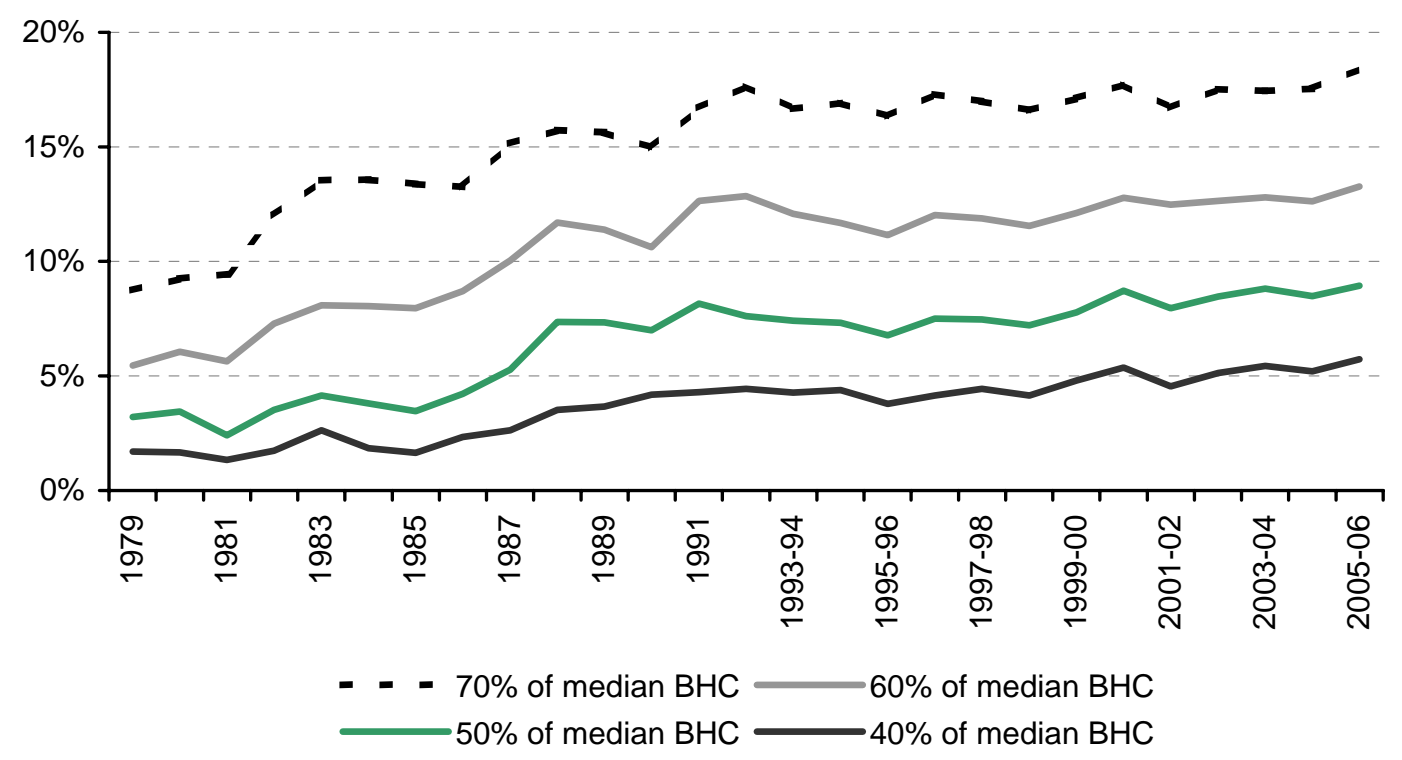

Note: Figures are presented for GB up until 2001-02 and then for the whole of the UK from 2002-03 onwards.

Source: Authors' calculations based on Family Expenditure Survey and Family Resources Survey, various years. 
Table 10. Decomposition of the rise in relative poverty amongst working-age non-parents (AHC), 1996-97 to 2005-06

\begin{tabular}{|c|c|c|c|c|c|c|c|}
\hline & \multicolumn{2}{|c|}{ Poverty rate } & \multicolumn{2}{|c|}{$\begin{array}{l}\text { Percentage of } \\
\text { population }\end{array}$} & \multirow[t]{2}{*}{$\begin{array}{c}\text { Incidence } \\
\text { effect }\end{array}$} & \multirow[t]{2}{*}{$\begin{array}{c}\text { Compositional } \\
\text { effect }\end{array}$} & \multirow{2}{*}{$\begin{array}{c}\text { Total } \\
\text { change in } \\
\text { poverty }\end{array}$} \\
\hline & 1996-97 & 2005-06 & $1996-97$ & 2005-06 & & & \\
\hline \multicolumn{8}{|l|}{ Single individuals } \\
\hline Full-time & $6.6 \%$ & $8.4 \%$ & $25.3 \%$ & $25.7 \%$ & $0.5 \%$ & $0.0 \%$ & $0.4 \%$ \\
\hline Part-time & $28.2 \%$ & $25.9 \%$ & $4.1 \%$ & $6.0 \%$ & $-0.1 \%$ & $0.2 \%$ & $0.1 \%$ \\
\hline Workless & $55.6 \%$ & $51.9 \%$ & $14.8 \%$ & $14.4 \%$ & $-0.5 \%$ & $-0.1 \%$ & $-0.7 \%$ \\
\hline \multicolumn{8}{|l|}{ Couples, no children } \\
\hline Self-employed & $14.5 \%$ & $15.8 \%$ & $7.8 \%$ & $7.3 \%$ & $0.1 \%$ & $0.0 \%$ & $0.1 \%$ \\
\hline Two full-time earners & $0.3 \%$ & $1.5 \%$ & $18.8 \%$ & $20.0 \%$ & $0.2 \%$ & $-0.2 \%$ & $0.0 \%$ \\
\hline $\begin{array}{l}\text { One full-time, } \\
\text { one part-time }\end{array}$ & $2.0 \%$ & $4.9 \%$ & $8.7 \%$ & $8.9 \%$ & $0.3 \%$ & $0.0 \%$ & $0.2 \%$ \\
\hline $\begin{array}{r}\text { One full-time, } \\
\text { one not working }\end{array}$ & $10.1 \%$ & $13.6 \%$ & $8.7 \%$ & $8.1 \%$ & $0.3 \%$ & $0.0 \%$ & $0.3 \%$ \\
\hline One or two part-time & $20.8 \%$ & $24.0 \%$ & $4.2 \%$ & $4.3 \%$ & $0.1 \%$ & $0.0 \%$ & $0.1 \%$ \\
\hline Workless & $39.2 \%$ & $42.0 \%$ & $7.7 \%$ & $5.4 \%$ & $0.2 \%$ & $-0.5 \%$ & $-0.3 \%$ \\
\hline $\begin{array}{l}\text { All working-age } \\
\text { non-parents }\end{array}$ & $17.2 \%$ & $17.5 \%$ & $100.0 \%$ & $100.0 \%$ & $1.0 \%$ & $-0.7 \%$ & $0.3 \%$ \\
\hline
\end{tabular}

Note: Poverty rates are measured as the proportion of the group with income below $60 \%$ of the GB population-wide AHC median income.

Source: Authors' calculations based on Family Resources Survey, 1996-97 and 2005-06.

poverty; the only differences are that we look at single individuals rather than lone parents and at couples without children rather than couples with children.

The table shows that the small rise in relative poverty amongst working-age non-parents over this period is the product of two offsetting trends: ${ }^{43}$

- Increased employment has led to compositional shifts towards family types with adults in work rather than not in work, and this leads to a beneficial compositional effect (having a minus sign in Table 10), acting to reduce relative poverty.

- On the other hand, the incidence effects act to increase relative poverty overall (being positive in the table), because most of the family types here have seen a rising risk of relative poverty over the period, and the most

\footnotetext{
${ }^{43} \mathrm{~A}$ decomposition of changes in relative poverty measuring incomes $\mathrm{BHC}$ (not shown, but available from the authors) reveals a larger (more positive) incidence effect, with all groups experiencing a rise in the risk of poverty.
} 
important (quantitatively) of these involve rises in the (low) risk of poverty for couples with at least one full-time worker.

Overall, though, poverty for this group rose slightly, meaning that the reduction in poverty brought about by increased employment was insufficient to offset the rising risk of relative poverty for particular family types.

\subsection{Absolute poverty}

All the poverty figures presented so far have been based on relative measures of poverty: that is, measures of poverty where the poverty line moves each year in line with median income growth. Tables 11 and 12 set out estimates of the number of individuals in poverty, where the poverty line is fixed in real terms at $60 \%$ of 1996-97 median income, measuring incomes AHC and BHC

Table 11. Absolute poverty: percentage of individuals in households with incomes below 60\% of 1996-97 median AHC income

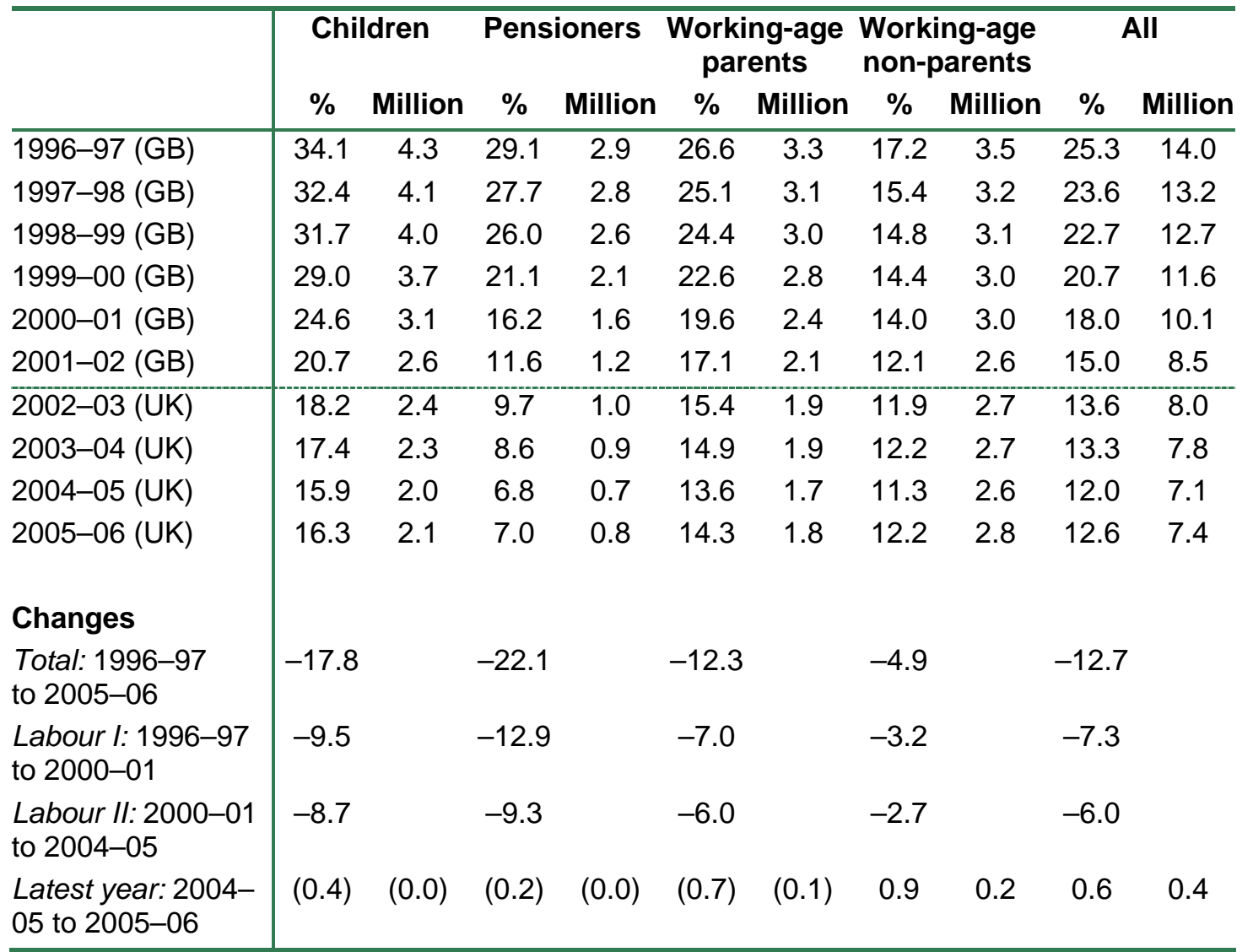

Notes: Reported changes may not equal the differences between the corresponding numbers due to rounding. Changes in parentheses are not significantly different from zero at the $5 \%$ level. Changes in the number of individuals in poverty are only shown where these can be calculated consistently at the UK level. All figures are presented using the modified OECD equivalence scale.

Source: Authors' calculations based on Family Resources Survey, various years. 
Table 12. Absolute poverty: percentage of individuals in households with incomes below 60\% of 1996-97 median BHC income

\begin{tabular}{|c|c|c|c|c|c|c|c|c|c|c|}
\hline & \multicolumn{2}{|c|}{ Children } & \multicolumn{2}{|c|}{ Pensioners } & \multicolumn{2}{|c|}{$\begin{array}{l}\text { Working-age } \\
\text { parents }\end{array}$} & \multicolumn{2}{|c|}{$\begin{array}{l}\text { Working-age } \\
\text { non-parents }\end{array}$} & \multicolumn{2}{|c|}{ All } \\
\hline & $\%$ & Million & $\%$ & Million & $\%$ & Million & $\%$ & Million & $\%$ & Millio \\
\hline 1996-97 (GB) & 26.7 & 3.4 & 24.6 & 2.4 & 20.2 & 2.5 & 12.0 & 2.5 & 19.4 & 10.8 \\
\hline 1997-98 (GB) & 25.8 & 3.3 & 23.7 & 2.4 & 19.5 & 2.4 & 11.4 & 2.4 & 18.6 & 10.4 \\
\hline 1998-99 (GB) & 24.1 & 3.1 & 23.8 & 2.4 & 18.0 & 2.2 & 10.7 & 2.2 & 17.7 & 9.9 \\
\hline 1999-00 (GB) & 21.0 & 2.7 & 20.2 & 2.0 & 16.4 & 2.0 & 10.4 & 2.2 & 15.8 & 8.9 \\
\hline 2000-01 (GB) & 17.2 & 2.2 & 17.5 & 1.8 & 13.5 & 1.6 & 10.4 & 2.2 & 13.9 & 7.8 \\
\hline $2001-02$ (GB) & 13.3 & 1.7 & 15.6 & 1.6 & 11.1 & 1.3 & 8.8 & 1.9 & 11.5 & 6.5 \\
\hline 2002-03 (UK) & 12.4 & 1.6 & 14.1 & 1.5 & 10.3 & 1.3 & 8.9 & 2.0 & 10.9 & 6.4 \\
\hline 2003-04 (UK) & 12.0 & 1.6 & 13.1 & 1.4 & 10.0 & 1.2 & 9.2 & 2.1 & 10.7 & 6.2 \\
\hline 2004-05 (UK) & 11.3 & 1.5 & 11.7 & 1.3 & 9.5 & 1.2 & 8.7 & 2.0 & 10.0 & 5.9 \\
\hline 2005-06 (UK) & 11.4 & 1.5 & 10.9 & 1.2 & 9.9 & 1.2 & 9.0 & 2.0 & 10.1 & 5.9 \\
\hline \multicolumn{11}{|l|}{ Changes } \\
\hline $\begin{array}{l}\text { Total: } 1996-97 \\
\text { to } 2005-06\end{array}$ & -15.3 & -1.9 & -13.7 & -1.3 & -10.3 & -1.3 & -3.0 & -0.4 & -9.4 & -4.9 \\
\hline $\begin{array}{l}\text { Labour I: 1996-97 } \\
\text { to } 2000-01\end{array}$ & -9.5 & -1.2 & -7.1 & -0.7 & -6.6 & -0.9 & -1.7 & -0.3 & -5.6 & -3.0 \\
\hline $\begin{array}{l}\text { Labour II: 2000-01 } \\
\text { to } 2004-05\end{array}$ & -5.9 & -0.7 & -5.8 & -0.5 & -4.1 & -0.4 & -1.7 & -0.2 & -3.9 & -1.9 \\
\hline $\begin{array}{l}\text { Latest year: } 2004- \\
05 \text { to 2005-06 }\end{array}$ & $(0.1)$ & $(0.0)$ & $(-0.8)$ & $(-0.1)$ & $(0.4)$ & $(0.0)$ & $(0.3)$ & $(0.1)$ & $(0.1)$ & $(0.0)$ \\
\hline
\end{tabular}

Notes: Reported changes may not equal the differences between the corresponding numbers due to rounding. Changes in parentheses are not significantly different from zero at the $5 \%$ level. Changes in the number of individuals in poverty are only shown where these can be calculated consistently at the UK level. All figures are presented using the modified OECD equivalence scale.

Source: Authors' calculations based on Family Resources Survey, various years.

respectively. Because this poverty line no longer has any link to current living standards, it is commonly known as an absolute poverty line. ${ }^{44}$ The tables show poverty for the population as a whole, and separately for children, pensioners and working-age adults.

There are currently 7.4 million individuals (12.6\% of the UK population) living in absolute poverty measuring incomes AHC, a statistically significant rise of 400,000 since 2004-05. Measuring incomes BHC, there are 5.9 million individuals in absolute poverty, the same as in 2004-05 (the rate of absolute

\footnotetext{
${ }^{44}$ The choice of a base year for an absolute poverty line is arbitrary, but 1996-97 is the one chosen by the government in Opportunity for All. Note that the absolute poverty tier of the government's child poverty target is assessed against 60\% of median income in 1998-99.
} 
poverty measuring incomes BHC and based on unrounded numbers has risen very slightly, from $10.0 \%$ to $10.1 \%$ ).

This is the first year since 1994-95 that the rate of absolute poverty has risen measuring incomes AHC (using the 1996-97 median income as a poverty line), and the first year since 1992 that it has risen measuring incomes BHC. Indeed, the average annual change in absolute poverty measuring incomes $\mathrm{AHC}$ between 1996-97 and 2004-05 was a fall of 1.7 percentage points: this adds to the impression that income and poverty changes between 2004-05 and 200506 were quite unusual. Of course, the rapid decline in absolute poverty between 1996-97 and 2004-05 means that absolute poverty in 2005-06 remains considerably lower than the respective levels in 1996-97.

There was also a small rise in absolute child poverty in 2005-06, of 0.4 percentage points (AHC) and 0.1 percentage points (BHC). These changes are not statistically different from zero, but they are unusual: it is the first time that absolute child poverty on this measure has risen since 1992.

Pensioners also saw a small rise in absolute poverty measuring incomes AHC, of 0.2 percentage points, but there was a fall in absolute pensioner poverty of 0.8 percentage points measuring incomes BHC. Neither of these changes is statistically different from zero. ${ }^{45}$

However, the rise in absolute poverty has been most noticeable for workingage non-parents, for whom the risk of falling into absolute poverty has risen by 0.9 percentage points (AHC) and 0.3 percentage points (BHC). The former of these is statistically different from zero, and this is not the first year that absolute poverty has risen amongst this group since 1996-97.

\section{Conclusions}

The changes in the distribution of income between 2004-05 and 2005-06 are sure to disappoint the government. Although patterns of year-on-year income changes are rarely statistically significant, the central estimates implied by the HBAI data are that income grew faster for the rich than for the poor: incomes amongst the poorest fifth of the UK fell by $0.4 \%$, while median income grew

\footnotetext{
${ }^{45}$ Note that it is not a contradiction for pensioner poverty to fall on a relative basis (as shown in Table 5) but to rise on an absolute basis (Table 11), both measuring incomes AHC, because the poverty lines are quite different: the relative poverty line in 2005-06 was £229 but the absolute poverty line was $£ 176$.
} 
by $1.0 \%$ and the incomes of the richest fifth rose by $1.5 \%$, though none of these changes is significantly different from zero or from one another. This pattern of income growth, which suggests a slight rise in inequality, is more similar to that seen under Thatcher than under Blair between 1996-97 and 2004-05. On the other hand, the overall change in the income distribution since 1996-97 is little altered by one more year of data: broadly, the income distribution became more equal between around the $15^{\text {th }}$ and $90^{\text {th }}$ percentiles, but it has grown more unequal at the very top and the very bottom. Accordingly, a measure of inequality that gives the ratio of the $90^{\text {th }}$ to the $10^{\text {th }}$ percentile of the income distribution shows falling inequality since 1996-97, but other measures that look at the whole distribution tend to show that inequality has risen, with the slight rise in the Gini coefficient (from 0.33 to 0.35) since 1996-97 once more being statistically significant. This overall small rise in inequality is, of course, much smaller in magnitude than the rise in inequality occurring during the 1980s: between 1979 and 1990, the Gini coefficient rose from a value of 0.25 to 0.34 .

The fact that median income grew by more than the incomes of those at the bottom of the income distribution meant that measures of relative poverty rose on a number of different thresholds, measuring incomes AHC or BHC, and by an amount that is unlikely to reflect sampling error. This represents the first rise in overall relative poverty since 1997-98, and the largest year-on-year rise since 1992. Of course, this should not deflect attention from the fact that relative poverty experienced its longest sustained fall between 1998-99 and 2004-05, and it remains considerably lower in 2005-06 than the level that the government inherited (21.6\% compared with 25.3\% measuring incomes AHC). But given that 2005-06 saw increases in entitlements to means-tested benefits and tax credits that were small relative to those in past years, it raises the question as to whether rises in relative poverty are inevitable in the UK without above-inflation (and probably above-earnings-growth) increases in a wide range of benefits received by low-income households or tax rises that affect the rich proportionately more than the poor.

The rise in child poverty in 2005-06 means that the government has fallen even further short of its target for child poverty in 2004-05 to be a quarter lower than it was in 1998-99: by 2005-06, child poverty had fallen by only $18.0 \%$ (BHC) or $14.0 \%$ (AHC). If the government is serious about halving child poverty by $2010-11$, then child poverty needs to fall by a further 1.1 million between now and 2010-11, an annual average decline of over 200,000 for the 
next five years following an annual average decline of less than 100,000 a year for the previous seven years.

Previous work estimated that extra spending on tax credits and child benefit of around $£ 4.5$ billion a year by 2010-11 would give the government a 50:50 chance of meeting its target. While child poverty in 2005-06 is higher, by around 100,000 children, than that implied by the forecasts made a year ago, Budget 2007 also announced considerable changes to tax credits and income tax which should reduce the child poverty rate. Our revised estimate taking into account the measures in Budget 2007 is that additional new spending of around $£ 4$ billion a year (on the per-child element of the child tax credit) by 2010-11 is still needed for the government to have a 50:50 chance of meeting its target.

However, what is now clearer than a year ago is that finding an extra $£ 4$ billion a year to spend on tax credits for families with children over and above what is assumed in the government's public finance forecasts will be possible only by a very tight spending settlement in the forthcoming Comprehensive Spending Review on areas of public services such as the NHS, defence, transport and environmental protection, or by making substantial (and as-yet unannounced) savings in other social security spending programmes. The government may decide that it need not yet earmark the resources for meeting its child poverty targets (the latest it can wait is Autumn 2009, when tax credits and benefit rates for April 2010 need to be announced), hoping, perhaps, for buoyant tax revenues or under-spending in other areas of government. Such a policy, though, increases the risk that either the child poverty target will be missed or that new tax-raising measures will be needed in future Budgets.

For groups other than children, the changes in poverty bring mixed blessings for the government. Pensioner poverty has continued to fall in relative terms, with a decline in poverty measuring incomes AHC of over a third since 199697. However, poverty amongst working-age adults without dependent children has risen to its highest level since consistent data first became available in 1961.

\section{Appendix 1. A comparison with the National Accounts}

It is useful to compare the HBAI estimates of changes in average income with estimates from other sources. The National Accounts have the advantage that they do not rely to the same extent on data gathered from samples, and so they are not subject to the same degree of statistical uncertainty as the HBAI data. 
However, they are quite limited in their use in analysing living standards, since they are only able to provide estimates of the mean; they do not allow us to assess the median or any other information about the distribution of income. It is also important to realise that the National Accounts do not allow us to measure living standards in exactly the same way as HBAI, so the change in average income they report is likely to differ from the HBAI series. One complication is that the 'household sector' as defined in the National Accounts includes bodies such as charities and most universities, as well as families. In addition, the HBAI measure of living standards adjusts for household size and composition in a different way from the 'per head' estimates from the National Accounts.

Table 13 gives growth rates since 1996-97 for a number of different series taken from the National Accounts, presented alongside mean BHC income growth in HBAI. Although not directly comparable, median BHC income growth in HBAI is included in the table for reference purposes. We also include figures on mean disposable income per household from the most recent ONS Family Spending report, which is based on data from the Expenditure and Food Survey (EFS). This is a national survey comparable in many ways to, but smaller in sample size than, the Family Resources Survey on which the HBAI statistics are based. The measure of disposable income provided in Family Spending is not constructed in the same way as the measure in HBAI; in particular, income is assessed on a per-household basis, and is therefore not adjusted for family size and composition at all.

The pattern of growth in mean GDP per head is broadly similar to that of mean HBAI income growth. Average annualised growth since 1996-97 (at 2.4\% per year in real terms) and average growth across each of the two parliaments (at $3.0 \%$ and $2.1 \%$ respectively) are very similar to those revealed in the HBAI data. The average change in 2005-06 is also very similar to that measured in HBAI. There are, however, some sizeable divergences in particular years. This may not be surprising, however, since national income includes the income of companies and the government as well as the income of households. ${ }^{46}$

\footnotetext{
${ }^{46}$ HBAI data will contain the income of companies that is distributed in dividends to households, but not the income that is distributed to pension funds or that is retained.
} 
Table 13. HBAI income growth compared with the National Accounts

\begin{tabular}{|c|c|c|c|c|c|}
\hline & $\begin{array}{c}\text { Mean } \\
\text { HBAI } \\
\text { BHC } \\
\text { income } \\
\text { (GB) }\end{array}$ & $\begin{array}{c}\text { Median } \\
\text { HBAI } \\
\text { BHC } \\
\text { income } \\
\text { (GB) }\end{array}$ & $\begin{array}{l}\text { Disposable } \\
\text { income per } \\
\text { household } \\
\text { (Expenditure } \\
\text { and Food } \\
\text { Survey) } \\
\text { (UK) }\end{array}$ & $\begin{array}{l}\text { GDP per } \\
\text { head } \\
\text { (UK) }\end{array}$ & $\begin{array}{c}\text { Real } \\
\text { household } \\
\text { disposable } \\
\text { income per } \\
\text { head } \\
\text { (UK) }\end{array}$ \\
\hline 1997-98 & $2.6 \%$ & $1.8 \%$ & $2.2 \%$ & $2.9 \%$ & $4.5 \%$ \\
\hline 1998-99 & $3.5 \%$ & $1.5 \%$ & $5.0 \%$ & $2.9 \%$ & $0.2 \%$ \\
\hline 1999-00 & $2.1 \%$ & $3.1 \%$ & $3.7 \%$ & $3.0 \%$ & $3.9 \%$ \\
\hline 2000-01 & $4.4 \%$ & $3.1 \%$ & $1.5 \%$ & $3.1 \%$ & $3.8 \%$ \\
\hline $2001-02$ & $4.4 \%$ & $4.9 \%$ & $6.5 \%$ & $1.7 \%$ & $3.0 \%$ \\
\hline 2002-03 & $1.3 \%$ & $2.0 \%$ & $0.4 \%$ & $1.9 \%$ & $1.7 \%$ \\
\hline $2003-04$ & $-0.4 \%$ & $0.0 \%$ & $-0.4 \%$ & $2.6 \%$ & $1.8 \%$ \\
\hline $2004-05$ & $1.4 \%$ & $1.0 \%$ & $2.2 \%$ & $2.4 \%$ & $1.1 \%$ \\
\hline $2005-06$ & $1.3 \%$ & $1.0 \%$ & $-0.4 \%$ & $1.3 \%$ & $1.9 \%$ \\
\hline Labour (1996-97 to 2005-06) & $2.3 \%$ & $2.0 \%$ & $2.3 \%$ & $2.4 \%$ & $2.4 \%$ \\
\hline \multicolumn{6}{|l|}{ Of which } \\
\hline Blair I (1996-97 to 2000-01) & $3.1 \%$ & $2.4 \%$ & $3.1 \%$ & $3.0 \%$ & $3.1 \%$ \\
\hline Blair II (2000-01 to 2004-05) & $1.7 \%$ & $2.0 \%$ & $2.2 \%$ & $2.1 \%$ & $1.9 \%$ \\
\hline $2004-05$ to $2005-06$ & $1.3 \%$ & $1.0 \%$ & $-0.4 \%$ & $1.3 \%$ & $1.9 \%$ \\
\hline
\end{tabular}

The series 'real household disposable income per head' from the National Accounts excludes the income of companies and the government. ${ }^{47}$ Average income growth under this measure is also broadly similar to HBAI income growth, showing average annualised income growth since $1996-97$ of $2.4 \%$ per year. There are also some considerable divergences in the growth rates of these series for individual years - for example, the disposable-income-per-head measure shows somewhat higher average income growth in the last year than both the HBAI and GDP-per-head measures.

The measure of disposable income from Family Spending, based on the EFS, also shows broadly comparable trends to the other income measures shown, though average income growth appears lower in the last year in this survey than according to the other series.

\footnotetext{
${ }^{47}$ Real household disposable income per head in the National Accounts does differ from the HBAl income measure in several important ways. For example, it includes imputed income from owner-occupation from the National Accounts and income that can be attributed to nonprofit organisations such as universities and charities.
} 
Despite differences between the series, all agree that income has grown by around $2.3 \%-2.4 \%$ on an annualised basis over the period 1996-97 to 2005-06 as a whole, and that mean income growth has slowed markedly since 2002-03. Further details of how the HBAI and National Accounts measures of income differ were provided in the appendix of IFS Election Briefing Note no. 9. ${ }^{48}$

\section{Acknowledgements}

The authors are very grateful for financial support from the Nuffield Foundation, grant number OPD/33658. The Nuffield Foundation is a charitable trust established by Lord Nuffield. Its widest charitable object is 'the advancement of social well-being'. The Foundation has long had an interest in social welfare and has supported this project to stimulate public discussion and policy development. Co-funding from the ESRC-funded Centre for the Microeconomic Analysis of Public Policy at IFS (grant number M535255111) is also very gratefully acknowledged. Data from the Family Resources Survey were made available by the Department for Work and Pensions, which bears no responsibility for the interpretation of the data in this Briefing Note. Material from the Family Expenditure Survey was made available by the Office for National Statistics through the ESRC Data Archive and has been used by permission of the Controller of HMSO. Any errors and all views expressed are those of the authors.

\footnotetext{
${ }^{48}$ M. Brewer, A. Goodman, J. Shaw and A. Shephard, Living Standards, Inequality and Poverty, IFS Election Briefing Note no. 9, 2005 (http://www.ifs.org.uk/bns/05ebn9.pdf).
} 